Article

\title{
Vehicle Sideslip Angle Estimation Based on Tire Model Adaptation
}

\author{
Kanwar Bharat Singh +(i) \\ Tire Vehicle Mechanics, The Goodyear Tire \& Rubber Company, L-7750 Colmar-Berg, Luxembourg; \\ kanwar-bharat_singh@goodyear.com \\ t The views and opinions expressed in this article are those of the author and do not necessarily represent the \\ views of the The Goodyear Tire \& Rubber Company.
}

Received: 11 December 2018; Accepted: 4 February 2019; Published: 9 February 2019

\begin{abstract}
Information about the vehicle sideslip angle is crucial for the successful implementation of advanced stability control systems. In production vehicles, sideslip angle is difficult to measure within the desired accuracy level because of high costs and other associated impracticalities. This paper presents a novel framework for estimation of the vehicle sideslip angle. The proposed algorithm utilizes an adaptive tire model in conjunction with a model-based observer. The proposed adaptive tire model is capable of coping with changes to the tire operating conditions. More specifically, extensions have been made to Pacejka's Magic Formula expressions for the tire cornering stiffness and peak grip level. These model extensions account for variations in the tire inflation pressure, load, tread depth and temperature. The vehicle sideslip estimation algorithm is evaluated through experimental tests done on a rear wheel drive (RWD) vehicle. Detailed experimental results show that the developed system can reliably estimate the vehicle sideslip angle during both steady state and transient maneuvers.
\end{abstract}

Keywords: vehicle sideslip; tire model; magic formula; state estimation; Kalman filter

\section{Introduction}

Precise information about critical tire-vehicle dynamic states is vital for the effective execution of vehicle control systems. There is unequivocal agreement that knowledge about additional states of a vehicle can significantly reduce the risk of accidents through effective design and implementation of advanced chassis control systems. As a result, the problem of vehicle state estimation has attracted much attention from researchers. In the realm of methods for estimating vehicle sideslip angle $(\beta)$, there exist two fundamental groups of methodologies: (a) model-based observers and (b) kinematics-based observers (Table 1).

Table 1. Vehicle sideslip estimation techniques.

\begin{tabular}{ccc}
\hline Approach & Underlying Principle & Reference \\
\hline Model Based Observer & $\begin{array}{c}\text { The sideslip angle model is typically based on the bicycle } \\
\text { model. The model can further include feedback of error } \\
\text { signals (the differences between the measured signals } \\
\text { and the ones predicted by the model), thus forming a } \\
\text { closed loop observer }\end{array}$ & {$[1]$} \\
\hline Kinematic Based Observer & $\begin{array}{c}\text { Rely on kinematic equations correlating the vehicle } \\
\text { longitudinal and lateral velocities with longitudinal and } \\
\text { lateral accelerations and the yaw-rate. These methods do } \\
\text { not depend on vehicle or tire-road friction parameters }\end{array}$ & [2] \\
\hline
\end{tabular}


The formulation for a typical model-based observer is as follows [1]:

$$
\beta=\frac{-m a_{y}-\frac{2 a C_{f}-2 b C_{r}}{v_{x}} r+2 C_{f} \delta}{2 C_{f}+2 C_{r}}
$$

where $\beta$ is the vehicle sideslip angle, $m$ is the vehicle mass, $\delta$ is the road wheel angle, $v x$ is the vehicle longitudinal speed, $\mathrm{a}$ and $\mathrm{b}$ are the distances of the front and rear axles from the vehicle center of gravity, $\mathrm{Cf}$ and $\mathrm{Cr}$ are the front and rear tire cornering stiffness, $\mathrm{r}$ is the measured yaw-rate and ay is the measured lateral acceleration.

The formulation for the kinematic based observer is as follows [2]:

$$
\beta=\int \frac{a_{y}+g \sin \theta}{v_{x}}-r
$$

where $\theta$ is the vehicle body roll angle.

To get a stable estimation of sideslip angle, the integration must be stabilized by a feedback error signal, e.g., the difference of measured lateral acceleration and the modeled one.

The performance of both these observers was experimentally evaluated on a rear-wheel drive (RWD) vehicle. The test vehicle was equipped with an automotive grade inertial measurement unit (IMU) and a global positioning system (GPS) - inertial navigation system (INS) of RT3000 class (specific model: RT3100) from the Oxford Technical Solutions Ltd for sideslip angle measurement (Figure 1). Inputs for the observers come from the automotive grade IMU. Measurement taken from the RT3000 unit is assumed to be the actual value, i.e. the ground truth for the vehicle sideslip angle.

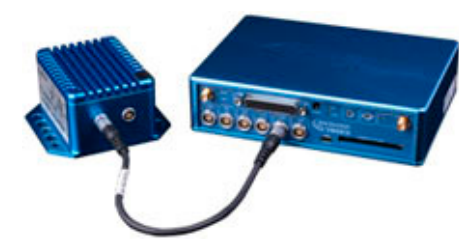

(a)

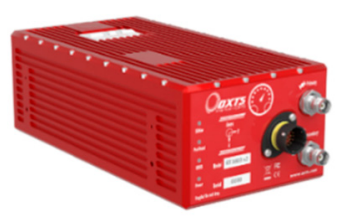

(b)

Figure 1. Instrumentation equipment: (a) Racelogic Inertial Measurement Unit (IMU) (RLVBIMU04) and (b) Oxford Technical Solutions RT3000.

Figure 2 shows measurements recorded during a sine-sweep test. Recorded signals were filtered using a low pass filter with a cut-off frequency of $5 \mathrm{~Hz}$.
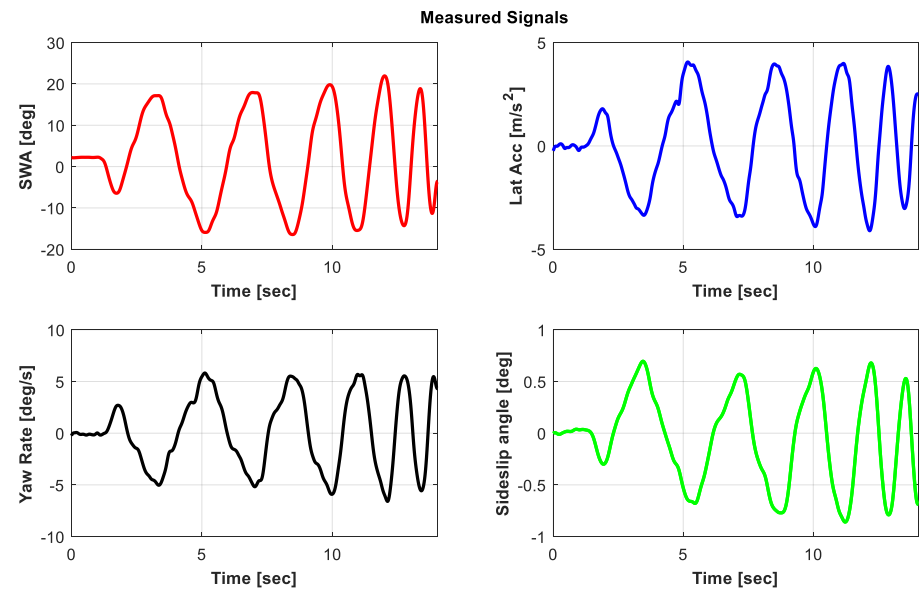

Figure 2. Experimental test measurements: sine-sweep test. 
These measurements were thereafter used to assess the performance of sideslip estimators using Equation (1) and Equation (2). Figure 3 presents the results for the kinematics-based observer. The observer is prone to drift due to bias errors in the accelerometer and gyroscope signals. This is despite the lateral acceleration signal $\left(a_{\mathrm{y}}\right)$ being compensated for by the vehicle body roll angle $(\theta)$.

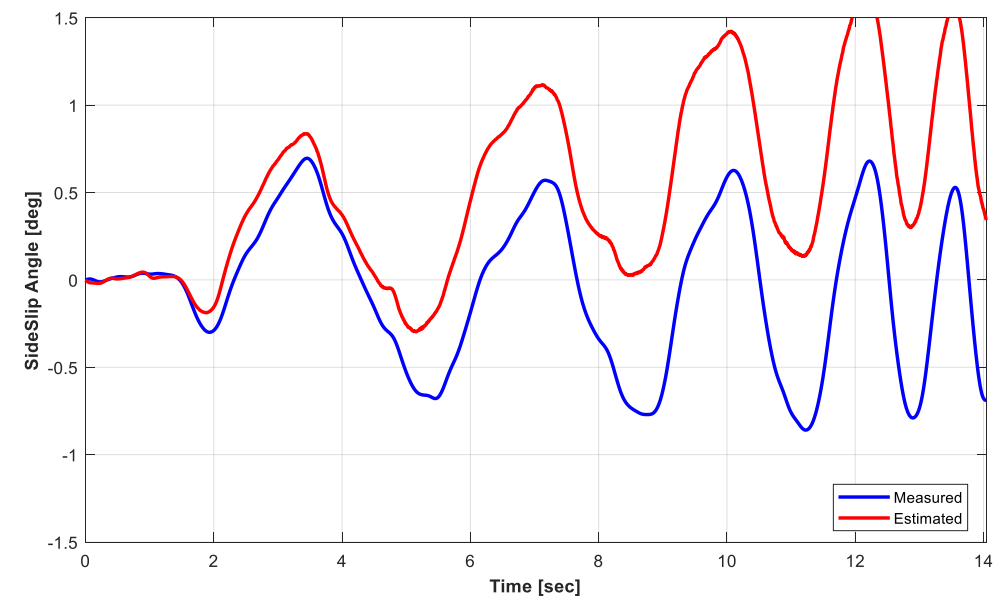

Figure 3. Performance of the kinematics-based observer.

In [2], the authors explain how the drift could be because of offset errors, i.e., the inertial measurement unit not being placed at the center of mass and possibly being misaligned with the vehicle axes. Correction of the offset error is crucial for avoiding the signal drift issue, particularly when integration is involved for state estimation [3]. The use of a forgetting factor in integration or a high pass filter may help, but only at the cost of severe phase lag and a deterioration in the estimation accuracy.

Figure 4 plots the results for the model-based observer. Estimates for the observer tend to deviate from the actual values because of mismatch between the actual vehicle/tire parameters and those used by the model.
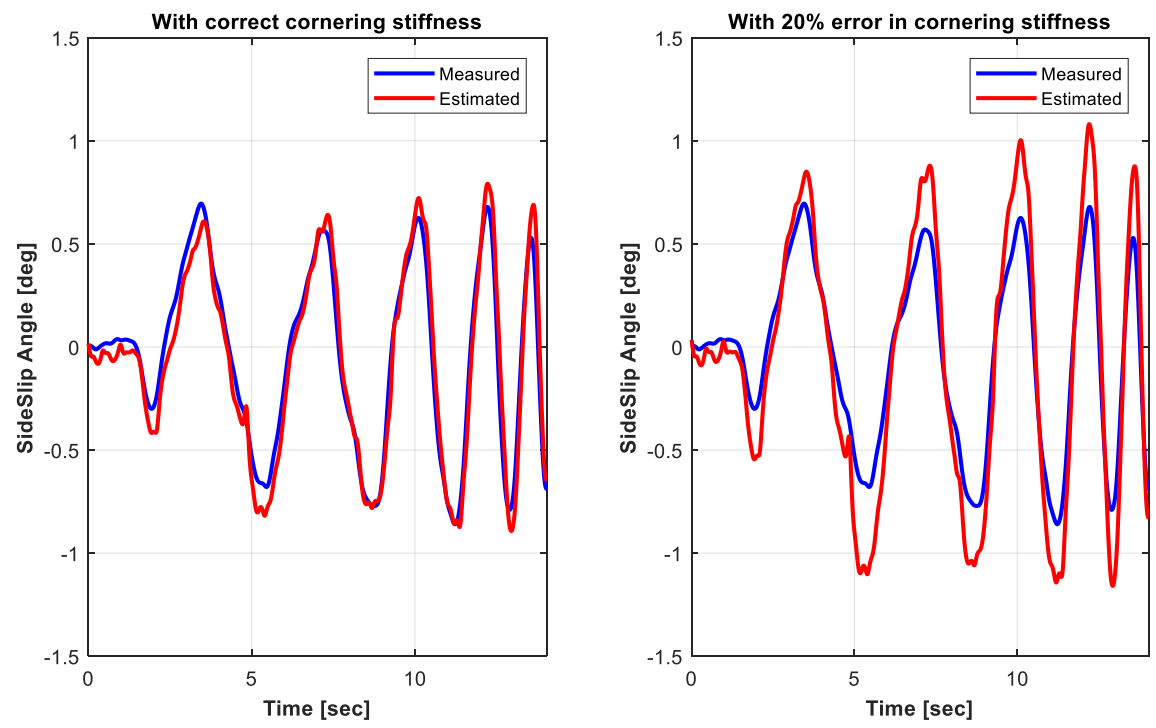

Figure 4. Performance of the model-based observer.

A key tire related parameter used in model-based estimators (based on the bicycle model) is the tire cornering stiffness. The tire cornering stiffness is known to be affected by several factors (Table 2) and consequently affects the accuracy of model-based estimators. 
Table 2. Factors affecting the tire cornering stiffness.

\begin{tabular}{ccc}
\hline Influencing Factor & $\begin{array}{c}\text { Effect on the Tire } \\
\text { Cornering Stiffness }\end{array}$ & Reasoning \\
\hline Inflation Pressure & Moderate & Caused by a variation in the carcass stiffness \\
and tread stiffness \\
Tire Wear & High & Caused by a variation in the tread stiffness \\
Tire Temperature & High & Caused by a variation in the rubber elasticity \\
Tire Aging & High & Caused by stiffening on tread rubber \\
\hline
\end{tabular}

Researchers through the years have proposed many algorithms for online estimation/adaptation of the tire cornering stiffness. For instance, in [4,5], algorithms for estimation of the tire cornering stiffness during high excitation maneuvers (steering frequency $>0.5 \mathrm{~Hz}$ ) are presented. Among all the methods studied, the beta-less method (Figure 5) has been found to have the highest potential for field implementation [6].

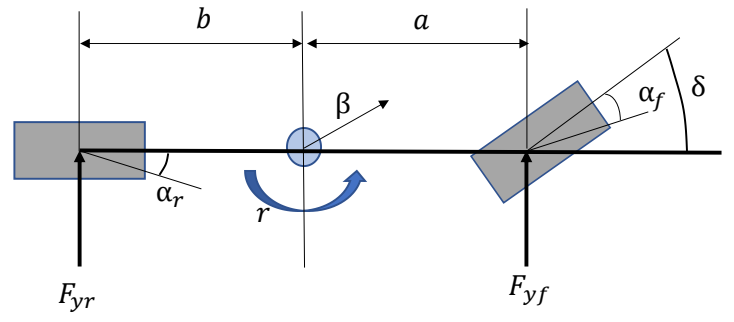

(a) Bicycle model for vehicle lateral dynamics

$$
F_{y f}=\left[\begin{array}{ll}
F_{y y} & \delta-\frac{(a+b) r}{\mathbb{v}_{x}}
\end{array}\right]\left[\begin{array}{l}
C_{f} \\
C_{y} \\
C_{f}
\end{array}\right]
$$

(b) Beta-less method derived by relating the front and rear tire (axle) forces

Figure 5. Formulation of the beta-less cornering stiffness estimator [4].

However, for most techniques presented in the literature [7], the estimation accuracy of the algorithm is only limited to transient maneuvers. This is also validated in the benchmarking work conducted as part of this study (Figure 6). The algorithm used applies the discrete-time Unscented Kalman filter (UKF) [8] for state estimation. To build a model-based UKF, the nonlinear bicycle model equations and linear tire model equations are converted to the discrete form by the first-order Euler method.

- The state vector $x_{k}$, at each time instant $k$ comprises of sideslip angle, yaw rate, front tire cornering stiffness and rear tire cornering stiffness.

- The measurement vector $y_{k}$ comprises of yaw rate and front and rear axle lateral forces.

Correct knowledge of process $(Q)$ and measurement noise $(R)$ covariance is crucial for the satisfactory working of the UKF estimator. The yaw rate and sideslip angle are modeled using system dynamic equations; therefore, low uncertainty is assigned to them. However, the front and rear tire cornering stiffness is not modeled at all; hence, they are given high uncertainties.

The observer estimation results are shown in Figure 6. The estimation accuracy of the observer is only restricted to transient maneuvers. It does not give satisfactory results during a steady state cornering maneuver. The estimates diverge from the actual measurements.

More recently, in $[9,10]$, an online cornering stiffness observer for low frequency maneuvers on public roads is presented. The estimation method presented shows good estimation results even under less extreme maneuvers on public roads. However, the relative error of the cornering stiffness estimate is still about $15 \%$.

In view of the above analysis, it is reasonable to conclude the following:

- Accurate knowledge of the tire cornering stiffness is crucial for ensuring good estimates of vehicle sideslip angle using model-based observers. 
- Observers for cornering stiffness estimation do not give satisfactory estimates during steady state maneuvers.

- The availability of a high-fidelity cornering stiffness model would facilitate the online computation of the vehicle sideslip angle.

The idea of simply utilizing a model-based estimate of the tire cornering stiffness might not have been very practical previously for the following reasons:

- Tires have a service life and get changed on a vehicle every few years. There is no way for the vehicle to know the properties of the new tire purchased by the customer.

- Customers in European countries typically have different tires mounted based on the season (summer or winter), mainly due to government mandated requirements. Tires built with different rubber compounds and structural properties (e.g. summer versus winter tires) behave very differently.

- During its normal service life, a tire is subjected to large variations in operating conditions such as ambient temperature, inflation pressure and changes in tread depth. The force and moment characteristics of the tire changes significantly due to each of these operating conditions.

Tire mounted sensors [11-14] are emerging as a promising technology capable of addressing these issues by uniquely identifying the tire on the vehicle and providing information about the tire operating conditions. Consequently, this presents opportunities for utilizing a model-based estimate of the tire cornering stiffness in vehicle state estimation. However, the model-based estimate of cornering stiffness needs to be very precise.
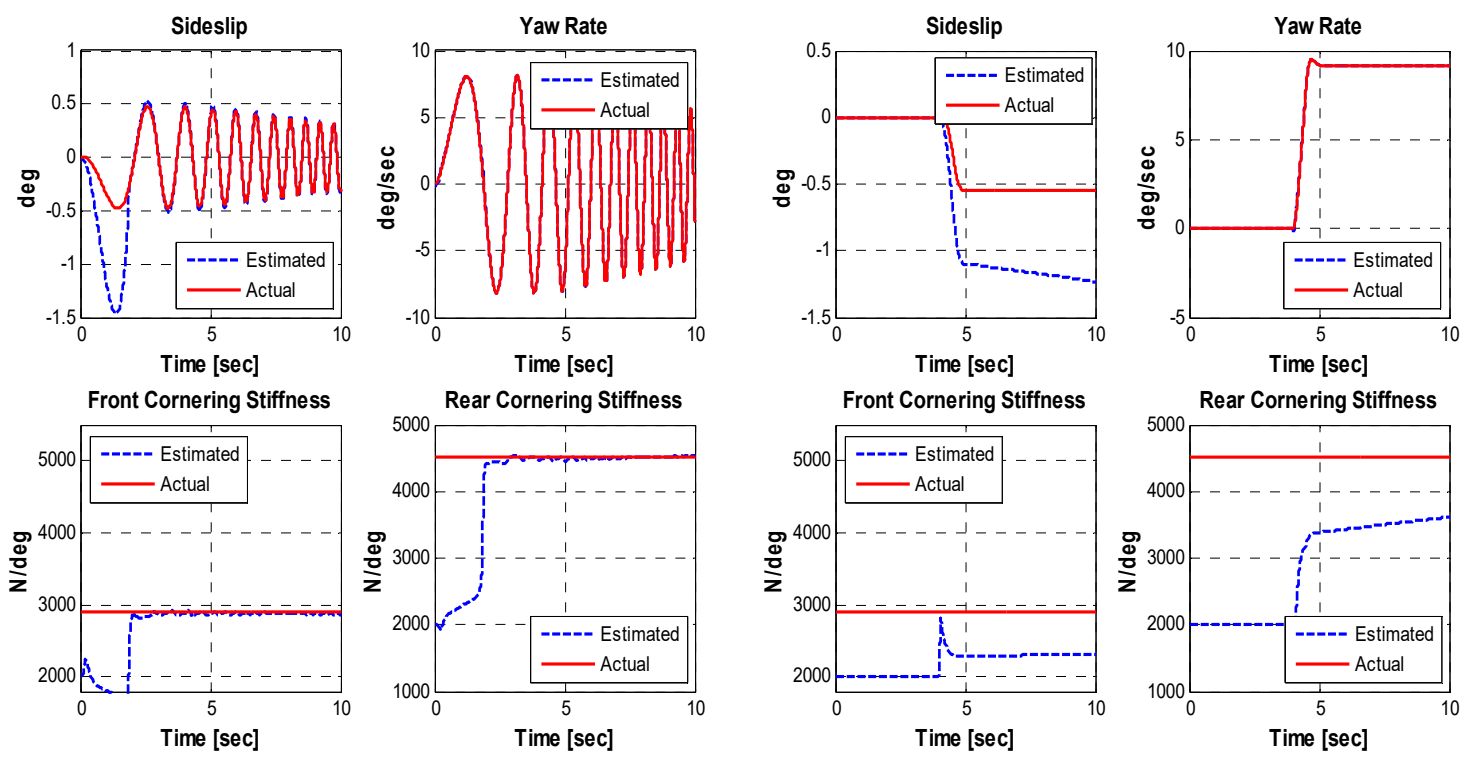

(a)

(b)

Figure 6. Cornering stiffness observer estimation performance. (a) Maneuver: sine-sweep 0.25-4 Hz-good convergence seen. (b) Maneuver: steady state circular test-no convergence.

This paper first addresses technical challenges associated with adapting the cornering stiffness expression of Pacejka's Magic Formula tire model [15] to tire inflation pressure, temperature, load and tread depth simultaneously. The rationale behind the selection of inflation pressure, temperature, load and tread depth is the availability of these signals from first-generation tire mounted sensor systems. Inflation pressure and temperature are available as direct sensor readings. Most tire mounted sensors [16-20] also include an accelerometer which enables estimation of the tire load based on a contact patch length based model (Figure 7). The contact patch length information is extracted from the 
radial acceleration signal by determining the distance between the zero crossing points of the signal, where the crossing points correspond to the leading and the trailing edge of the tire. More details regarding the load estimation algorithm can be found in a previous publication [21] by the author. Alternatively, in [22], an empirical model is used to describe the shape of the radial acceleration signal. Tire load is treated as an unknown parameter and is estimated to use an extended Kalman filter (EKF) observer. Accurate load estimation is demonstrated in cases of constant as well as changing forward velocity of the vehicle.

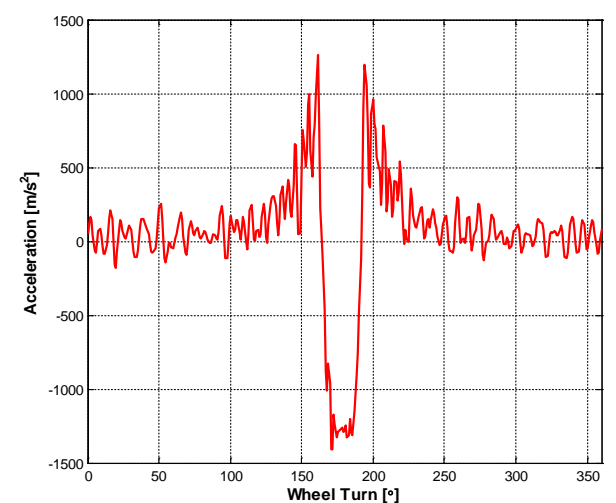

(a) Measured radial acceleration signal

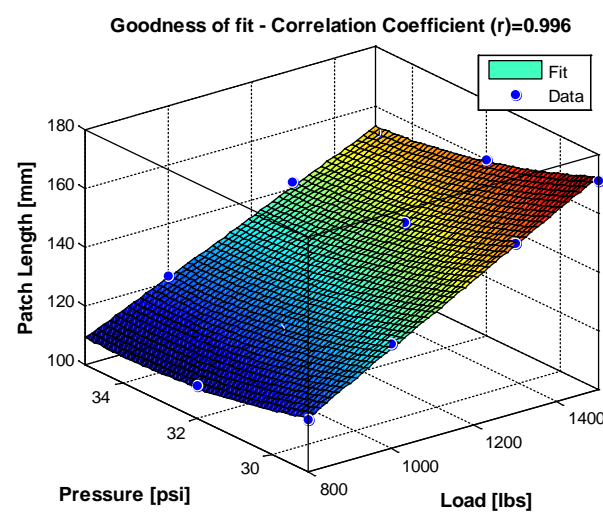

(b) Load estimation model training

Figure 7. Tire load estimation using a tire mounted accelerometer.

The remaining tire tread depth can also be extracted by employing time and frequency domain feature extraction techniques to the tire accelerometer signal (Table 3).

Table 3. Proposed techniques for tread depth estimation using tire mounted sensors.

\begin{tabular}{ccc}
\hline Measured Signal & Underlying Physics & Reference \\
\hline Tangential acceleration & $\begin{array}{c}\text { Monitors change in the tire } \\
\text { vibrational characteristics between } \\
\text { the frequency range 1000-3000 Hz } \\
\text { Monitor radial acceleration in the } \\
\text { pre-footprint region between } \\
\text { frequency range 1000-1700 Hz } \\
\text { Radial acceleration }\end{array}$ & U.S. Patent 8061191 [23] \\
Radial acceleration & internal radius & U.S. Patent 8775017 [24] \\
\hline
\end{tabular}

Hence, tire mounted sensors are expected to deliver key inputs required for adaptation of the cornering stiffness model. Once adaptation of the cornering stiffness model is achieved, estimation of vehicle sideslip angle is realized through usage of the adapted tire model.

The main contributions of this paper are as follows:

- Quantification of influence of operating conditions on tire cornering stiffness.

- Extension of cornering stiffness expression for Pacejka's Magic Formula to inflation pressure, temperature, load and tread depth.

- A novel framework for estimating vehicle sideslip angle.

The contents of this paper are organized as follows: Section 2 presents experimental results quantifying the influence of tire inflation pressure, tread depth, load, and temperature on the tire cornering stiffness. Section 3 presents details about an improved Magic Formula (MF) cornering stiffness model adapted to cope with changes in the tire operating conditions. Section 4 proposes an estimation procedure for vehicle sideslip angle using the cornering stiffness adaptation model, and conclusions are finally given in Section 5 . 
2. Quantifying the Influence of Variations in the Tire Inflation Pressure, Tread Depth, Load and Temperature on the Tire Cornering Stiffness

Over the years, various developments have been made to extend tire models to improve their prediction capabilities under various operating conditions [26-31]. With the objective of quantifying the influence of variations in the tire inflation pressure, tread depth, load, and temperature on the tire cornering stiffness, experiments were conducted on the Flat-Trac®machine (Figure 8).

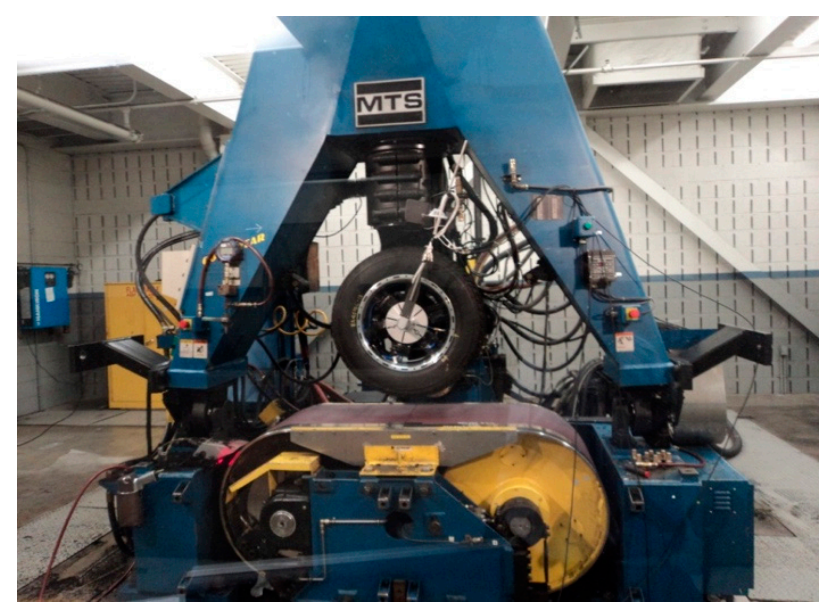

Figure 8. Flat-Trac ${ }^{\circledR}$ machine.

The sensitivity study was conducted for a high-performance summer tire. In addition to this, the influence of different constructions such as summer and all-season tires were also analyzed as vehicles in European countries typically have different tires mounted based on the season (summer or winter), mainly due to government mandated requirements. In the first round of tests, the influence of temperature was eliminated by keeping the slip angle sweep rate and the tire speed constant (Table 4).

- To evaluate the influence of the inflation pressure on the tire characteristics, four levels of pressure were analyzed: (a) 33 psi, (b) 37 psi, (c) 41 psi and (d) 45 psi.

- To evaluate the influence of the tire tread depth on the tire characteristics, three levels of tread depth were analyzed: (a) full tread depth, (b) 60\% of full tread depth and (c) 30\% of full tread depth.

- To evaluate the influence of the tire load on the tire characteristics, five levels of normal load were analyzed: (a) 33\% of nominal load, (b) 67\% of nominal load, (c) 100\% of nominal load. (d) 133\% of nominal load and (e) $167 \%$ of nominal load.

Table 4. Variable dependency chart.

\begin{tabular}{ccccccc}
\hline & $\begin{array}{c}\text { Tire Surface } \\
\text { Temperature }\end{array}$ & $\begin{array}{c}\text { Tire Bulk } \\
\text { Temperature }\end{array}$ & $\begin{array}{c}\text { Inflation } \\
\text { Pressure }\end{array}$ & $\begin{array}{c}\text { Normal } \\
\text { Load }\end{array}$ & Speed & Tread Depth \\
\hline $\begin{array}{c}\text { Cornering } \\
\text { Stiffness }\end{array}$ & $\begin{array}{c}\mathrm{x} \\
(\sim \text { constant })\end{array}$ & $\begin{array}{c}\mathrm{x} \\
(\sim \text { constant })\end{array}$ & $\checkmark$ & $\checkmark$ & $\begin{array}{c}\text { x } \\
\text { (constant) }\end{array}$ & $\checkmark$ \\
\hline
\end{tabular}

$\checkmark$ : varied. $x$ : kept constant.

The following sub-sections present results of the sensitivity analysis study.

\subsection{Influence of Inflation Pressure}

Figure 9 shows the cornering stiffness-inflation pressure dependency curves. The key conclusion reached about the cornering stiffness of a tire is that an increase in the tire inflation pressure has two counteracting effects: 
- A lower cornering stiffness at low vertical loads and a higher cornering stiffness at high vertical loads. These effects are clearly visible in Figure 9. The first effect is caused by the decreasing contact length because of the increased vertical stiffness from the increased inflation. A decrease of contact length (smaller surface area) results in a decrease of cornering stiffness. In the range of high vertical loads, this effect may also be present, but it is not dominant.

- A lower inflation pressure, and consequently a less stiff carcass, results in more rotation of the contact patch. This leads to lower lateral force for the same slip angle, which results in a lower cornering stiffness at high vertical loads. Conversely, a higher inflation pressure, and consequently a stiffer carcass, results in less rotation of the contact patch. This leads to higher lateral force for the same slip angle, which results in a higher cornering stiffness at high vertical loads.

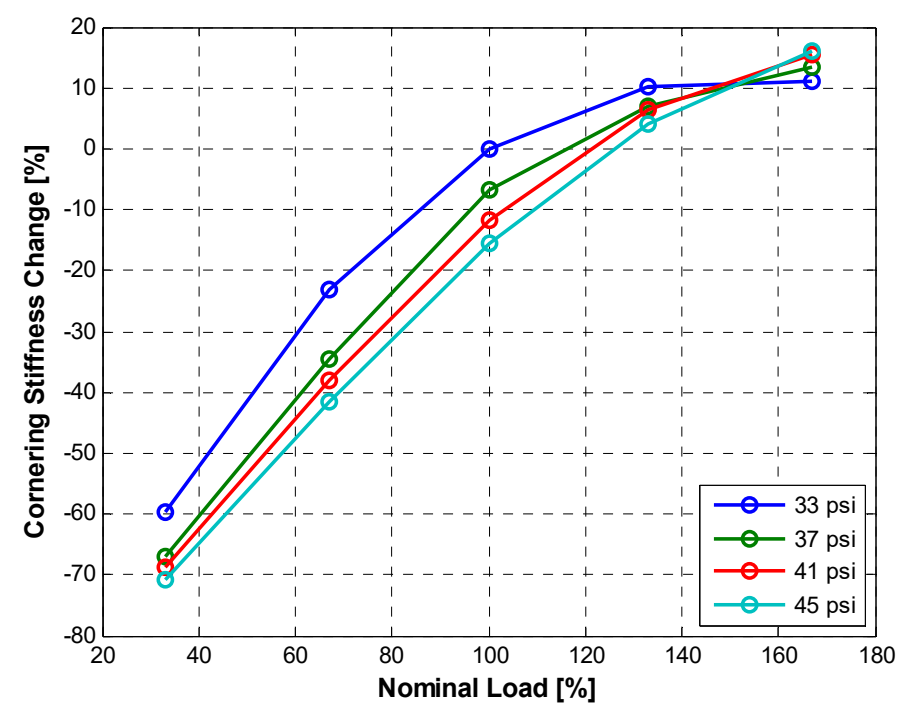

Figure 9. Influence of inflation pressure on the tire cornering stiffness.

\subsection{Influence of Tread Depth}

As expected, a change in the tire tread depth significantly influences the cornering stiffness characteristics of the tire (Figure 10).

The key conclusions reached about the tread depth effects are captured in Figures 11 and 12.

- Lower tread depth results in a higher cornering stiffness.

- At higher loads, carcass stiffness is the dominant component of cornering stiffness. Hence, even a large change in the tread depth only results in a smaller change in the cornering stiffness.

- For a tire with a lower tread depth, the cornering stiffness properties are dominated by the carcass stiffness characteristics.

- As explained previously, lowering the tire inflation pressure decreases the carcass stiffness, which explains the saturation trends seen in the CS curve.

- Furthermore, the saturation starts even earlier for a tire with a lower tread depth due to the dominant effect of carcass stiffness. 


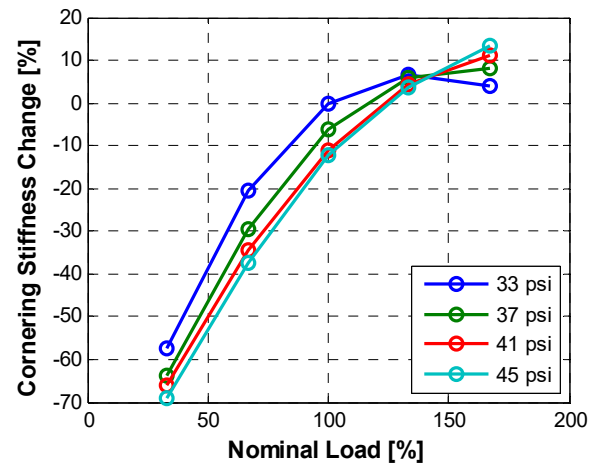

(b)

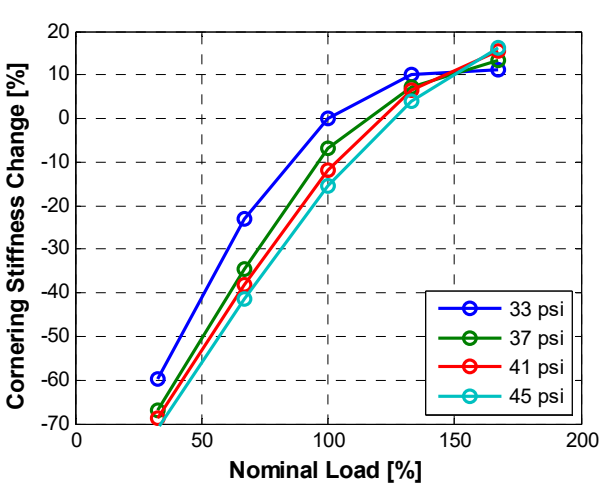

(a)

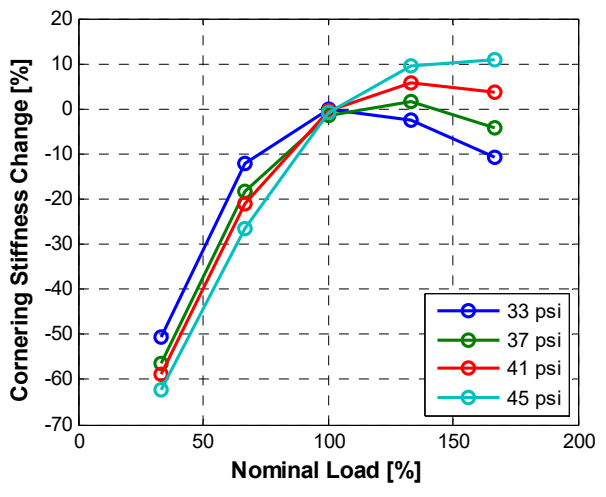

(c)

Figure 10. Cornering stiffness versus inflation pressure-influence of tire tread depth. (a) Full tread depth, (b) 60\% tread depth, (c) 30\% tread depth.

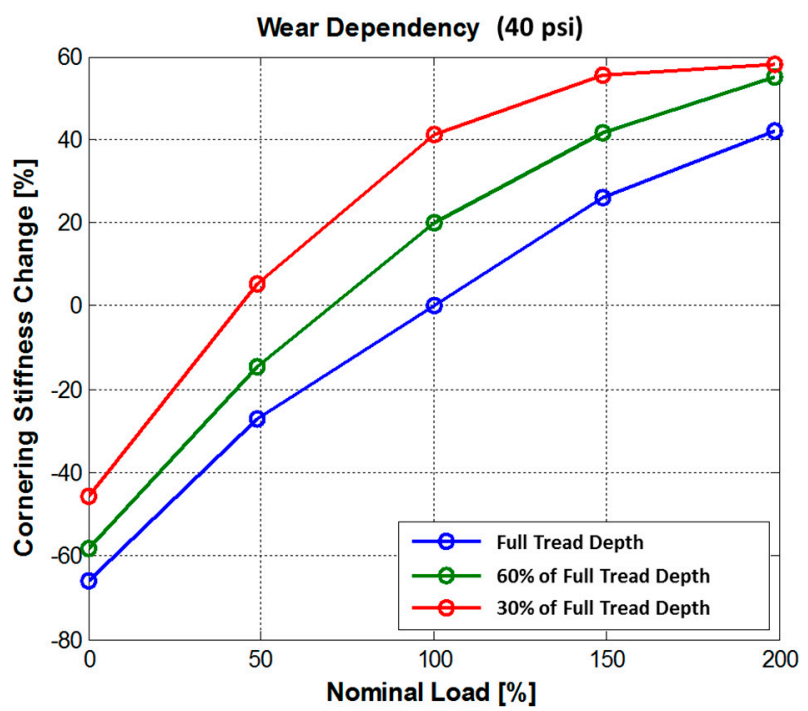

Figure 11. Wear dependency effects under constant inflation pressure conditions. 


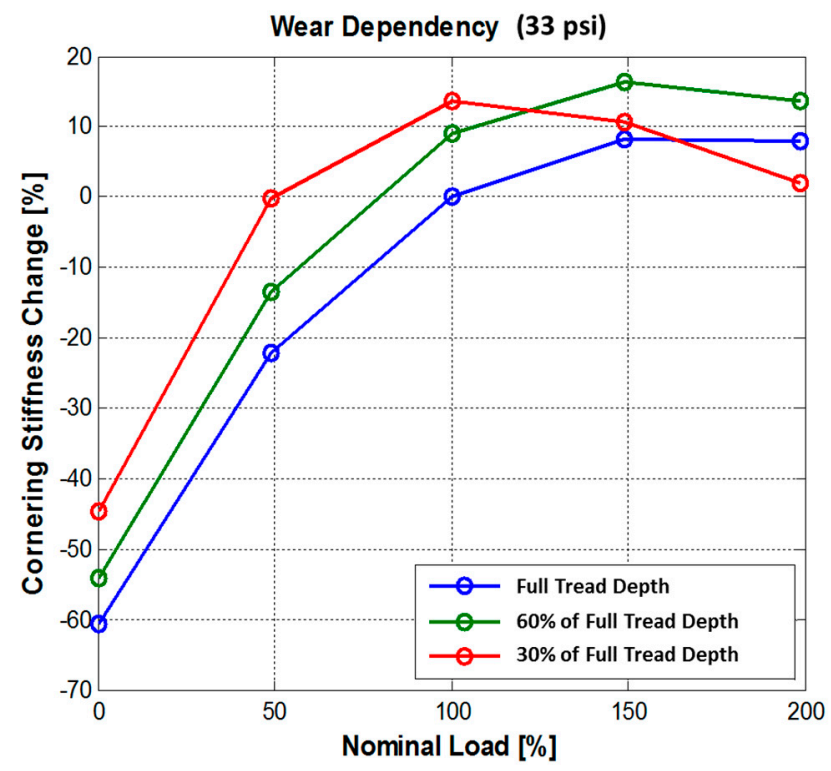

Figure 12. Wear dependency effects under constant inflation pressure conditions.

\subsection{Influence of Normal Load}

The tire cornering stiffness exhibits a non-linear dependence on the tire load (Figure 13). There are two load-dependent parameters affecting the tire cornering stiffness. The first load-dependent parameter is the tire contact patch length. Typically, the tire patch length changes with tire load in an order between 1 and 2. The second load-dependent parameter is the lateral elastic stiffness, which in turn is due to both the rubber tread elasticity and tire structure lateral compliance.

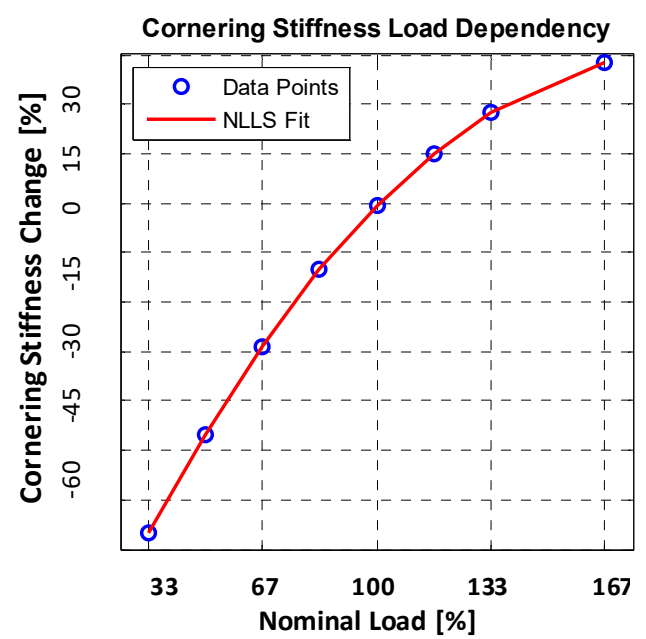

Figure 13. Influence of normal load on the tire cornering stiffness.

\subsection{Influence of Temperature on the Tire Characteristics of Interest}

A second set of tests were run on the Flat-Trac ${ }^{\circledR}$ machine to include the influence of temperature. The procedure consisted of running the test on new tires without a warm-up or break-in procedure. The tires were tested through 23 slip sweeps at one load and one camber condition. IR pyrometers were installed on the Flat-Trac ${ }^{\circledR}$ machine, allowing tire temperatures to be recorded throughout each test (Figure 14). 

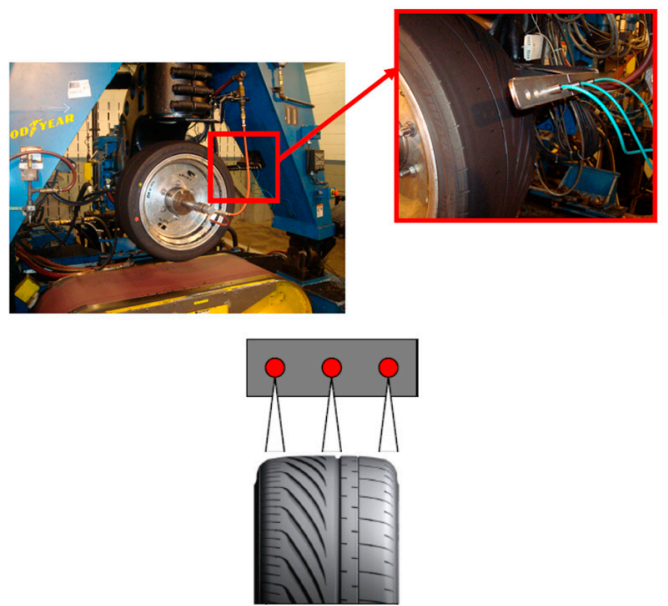

Figure 14. Tire temperature apparatus installed on the Flat-Trac®test machine.

The IR pyrometers give the machine the capability to record tire shoulder and centerline surface temperatures. Figure 15 shows the cornering stiffness temperature dependency curves.

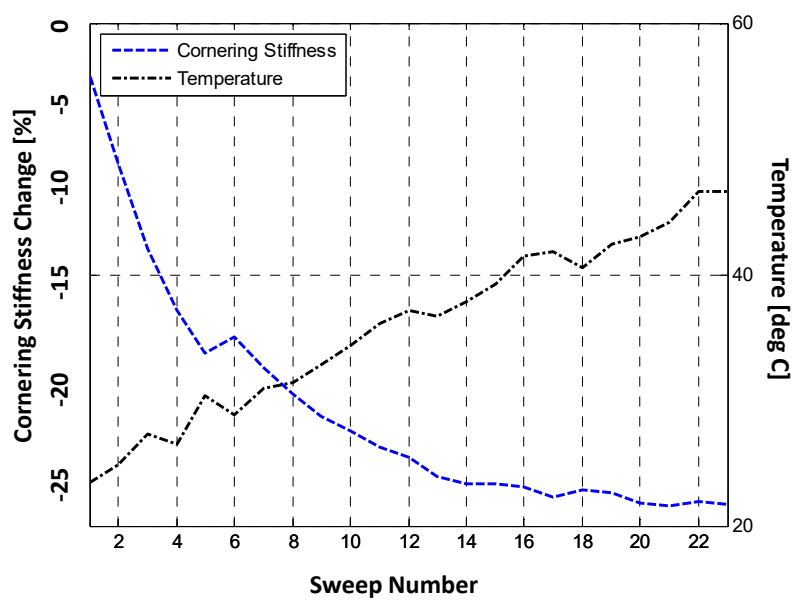

Figure 15. Influence of temperature on the tire cornering stiffness.

The influence of temperature can be mainly attributed to two main visco-elastic properties of rubber, which change with temperature.

- The storage modulus or tread rigidity, which influences cornering stiffness. This changes due to the bulk temperature of the tire.

- The coefficient of friction decides the peak lateral grip of the tire. This parameter is only influenced by the surface temperature of the tire at the road interface.

Table 5 presents a summary of the sensitivity analysis, determining the influence of variations in the tire inflation pressure, tread depth, normal load, and temperature on the tire cornering stiffness.

Table 5. Summary of dependencies.

\begin{tabular}{ccccccc}
\hline & $\begin{array}{c}\text { Tire Surface } \\
\text { Temperature }\end{array}$ & $\begin{array}{c}\text { Tire Bulk } \\
\text { Temperature }\end{array}$ & $\begin{array}{c}\text { Inflation } \\
\text { Pressure }\end{array}$ & $\begin{array}{c}\text { Normal } \\
\text { Load }\end{array}$ & $\begin{array}{c}\text { Rolling } \\
\text { Speed }\end{array}$ & $\begin{array}{c}\text { Tread } \\
\text { Depth }\end{array}$ \\
\hline $\begin{array}{c}\text { Cornering } \\
\text { Stiffness (CS) }\end{array}$ & $\begin{array}{c}\text { High } \\
\text { Dependency }\end{array}$ & $\begin{array}{c}\text { High } \\
\text { Dependency }\end{array}$ & $\begin{array}{c}\text { High } \\
\text { Dependency }\end{array}$ & $\begin{array}{c}\text { High } \\
\text { Dependency }\end{array}$ & $\begin{array}{c}\text { Negligible } \\
\text { Dependency }\end{array}$ & $\begin{array}{c}\text { High } \\
\text { Dependency }\end{array}$ \\
\hline
\end{tabular}

A quantifiable measure of the influence of the tire operating conditions on the cornering stiffness is summarized in Table 6. 
Table 6. Sensitivity analysis—summary.

\begin{tabular}{|c|c|c|c|c|}
\hline \multirow{2}{*}{ Tire Type } & & \multicolumn{3}{|c|}{ Factors Influencing Tire Characteristics } \\
\hline & & Pressure & Tread Depth & Temperature \\
\hline $\begin{array}{l}\text { Summer Tire } \\
\text { (High } \\
\text { Performance) }\end{array}$ & Cornering Stiffness & $\begin{array}{l}10 \% \text { increase with a } \\
20 \% \text { change in } \\
\text { inflation pressure } \\
\text { from nominal } \\
\text { conditions }\end{array}$ & $\begin{array}{c}30 \% \text { increase with a } \\
60 \% \text { decrease in } \\
\text { tread depth }\end{array}$ & $\begin{array}{c}20-25 \% \text { drop from } \\
\text { cold to hot tire } \\
\text { conditions } \\
\left(^{*} \text { strongly }\right. \\
\text { influenced } \\
\text { by the tire bulk } \\
\text { temperature })\end{array}$ \\
\hline
\end{tabular}

The next section of this paper presents details about an improved Magic Formula (MF) tire model adapted to cope with changes in the tire operating conditions.

\section{Magic Formula (MF) Cornering Stiffness Adaptation}

This section describes an extension to the widely used Magic Formula tire model. More specifically, an extension has been made to the Magic Formula expression for tire cornering stiffness, the details of which are described below.

Based on the Pacejka tire model formulation, the expression for tire cornering stiffness (BCD) is given as:

$$
B C D=a_{3} \sin \left(2 \arctan \left(\frac{F_{z}}{a_{4}}\right)\right)
$$

where $a_{3}=$ maximum cornering stiffness (at camber angle $\left.(\gamma)=0\right), \quad a_{4}=$ load at maximum cornering stiffness, $F_{z}=$ load on the tire.

In this study, the parameters ' $\mathrm{a} 3$ ' and ' $\mathrm{a} 4$ ' were calculated using the nonlinear least-squares (NLLS) curve fitting algorithm. The curve fitting results are shown in Figure 16.

To capture the pressure dependency, a second-order pressure scaling term was used for the parameter ' $\mathrm{a} 3$ ' and a first-order pressure scaling term was used for the parameter ' $\mathrm{a} 4$ ', as shown in the expression below.

$$
B C D=\left(a_{31} x^{2}+a_{32} x+a_{33}\right) \sin \left(2 \arctan \left(\frac{F_{z}}{a_{41} x+a_{42}}\right)\right)
$$

where $\mathrm{x}=$ pressure.

Model fitting results are shown in Figure 17.

The above analysis was repeated for tires with different levels of tread depth, with the underlying objective of capturing both the inflation pressure and tread depth effects simultaneously. To capture the tread depth dependency, second-order scaling terms were used to adapt the parameters 'a31', 'a32', 'a33', 'a41' and 'a42' to tread depth changes.

Shown below in Equation (10) is the modified expression for cornering stiffness with inflation pressure and tread depth adaptation terms.

$$
\begin{aligned}
B C D= & \left(\begin{array}{c}
\left(a_{311} y^{2}+a_{312} y+a_{313}\right) x^{2}+\left(a_{321} y^{2}+a_{322} y+a_{323}\right) x+ \\
\left(a_{331} y^{2}+a_{332} y+a_{333}\right)
\end{array}\right) . \\
& \sin \left(2 \arctan \left(\frac{F_{z}}{\left(\left(a_{411} y^{2}+a_{412} y+a_{413}\right) x+\left(a_{421} y^{2}+a_{422} y+a_{423}\right)\right)}\right)\right)
\end{aligned}
$$

where $\mathrm{x}=$ pressure and $\mathrm{y}=$ tread depth.

The performance of the adapted model was tested against measurement data and it showed good performance for the full range of inflation pressures and tread depths. As an illustrative example, model fitting results for a high-performance summer tire are shown in Figure 18. 

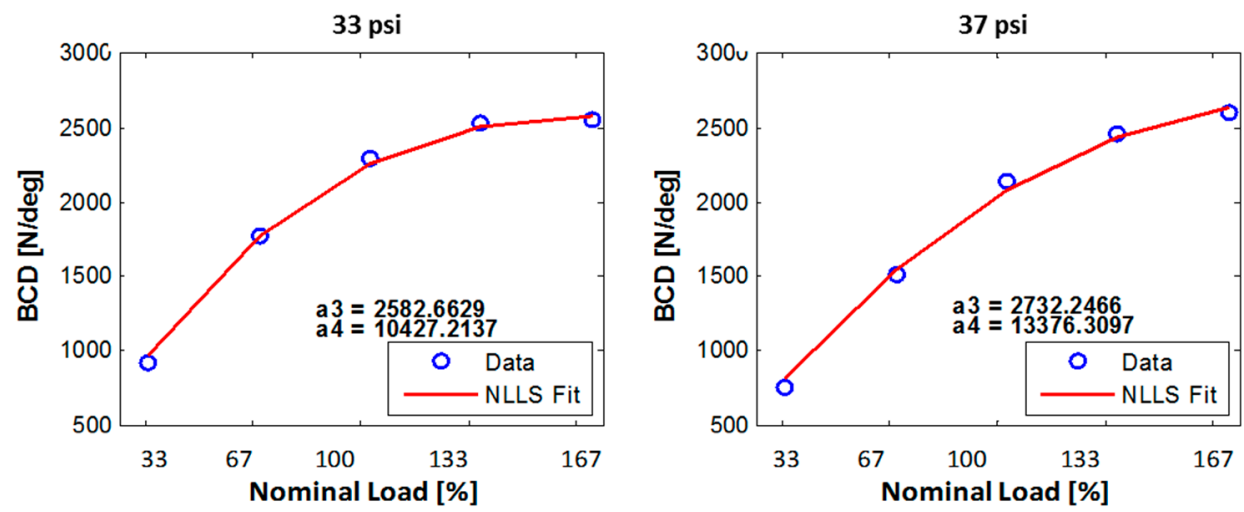

$41 \mathrm{psi}$
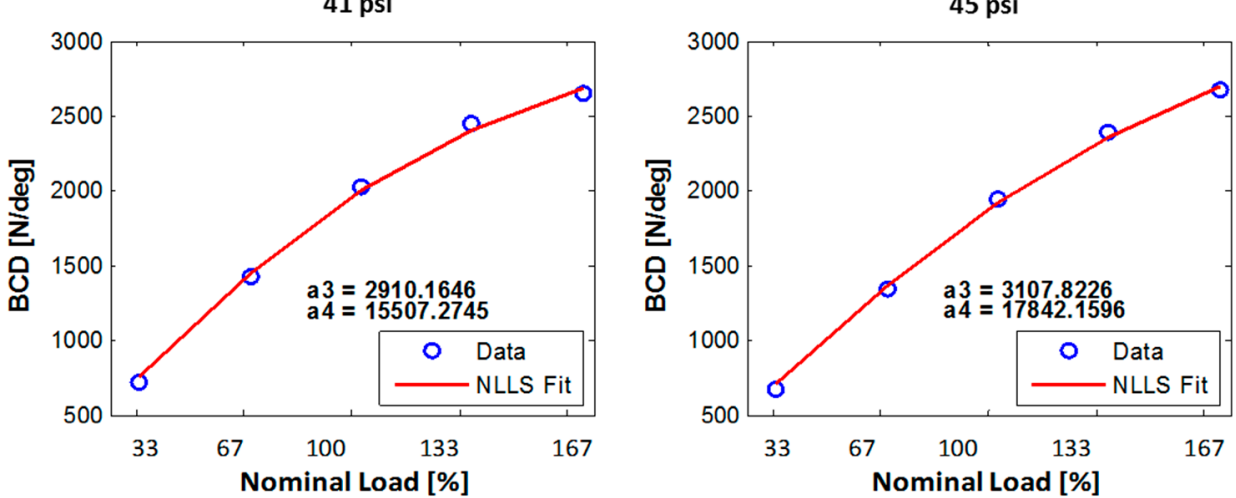

Figure 16. Nonlinear least-squares (NLLS) fitting results-' $a 3$ ' and 'a4' coefficient. $B C D=$ tire cornering stiffness.

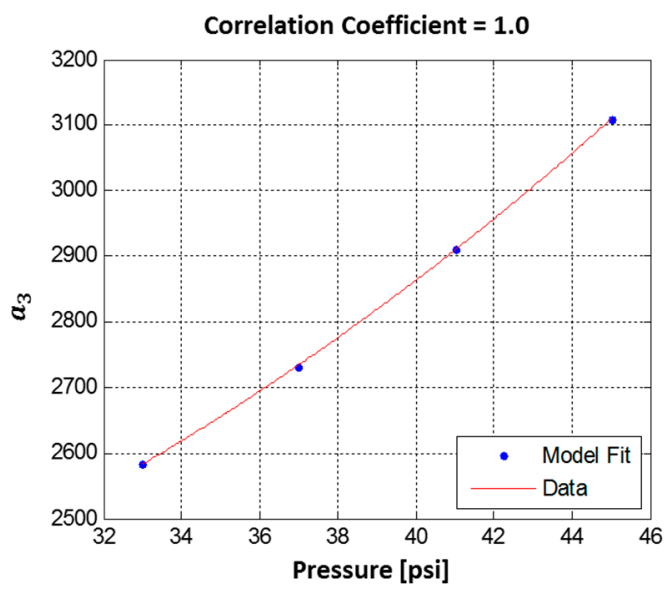

(a)

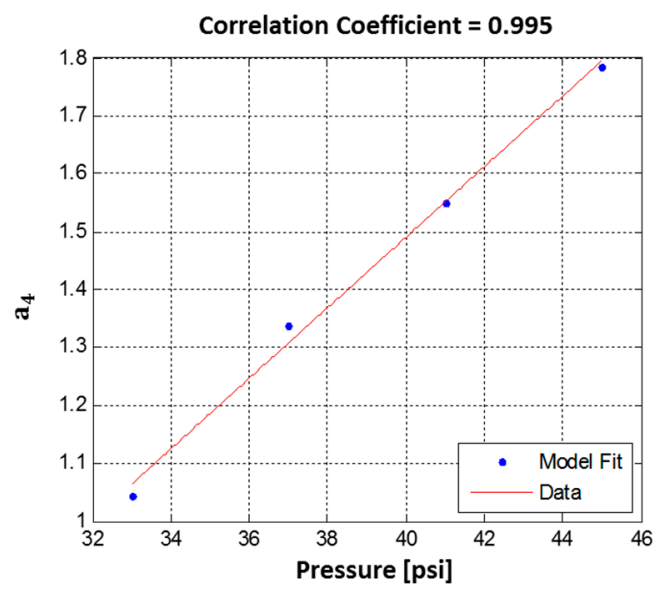

(b)

Figure 17. Model fitting results. (a) 'a3' pressure adaptation, (b) 'a4' pressure adaptation. 


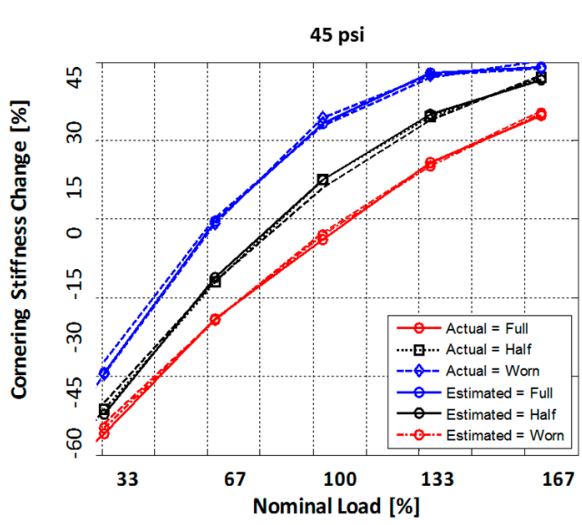

(a)

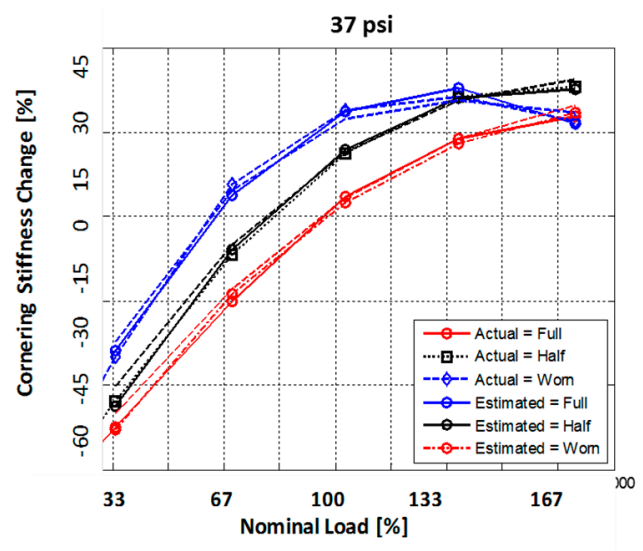

(c)

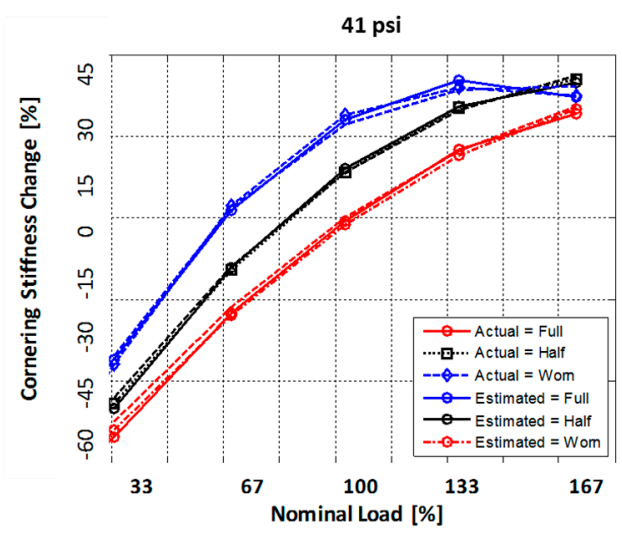

(b)

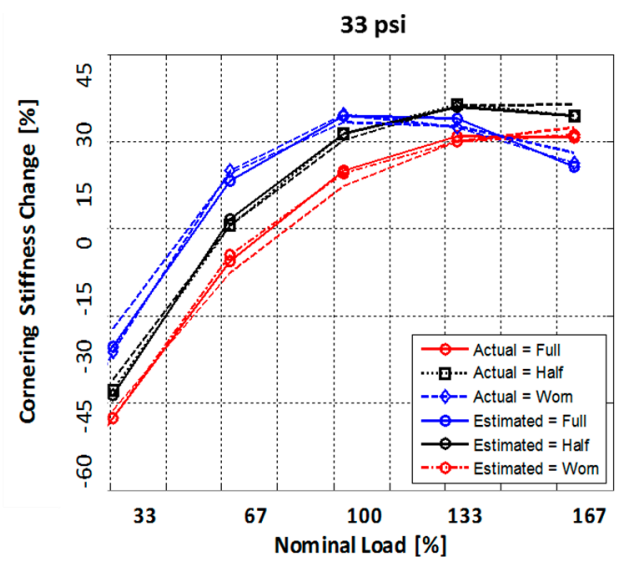

(d)

Figure 18. Tire cornering stiffness: actual (measurement) versus estimated (using adapted model). Model fitting performance at: (a) 45 psi, (b) 41 psi, (c) 37 psi and (d) 33 psi.

As a final step, a second-order temperature dependent scaling factor was used to cope with the changes in the tire temperature (Figure 19). More specifically, the term "tire temperature" as used herein refers to the tire surface temperature.

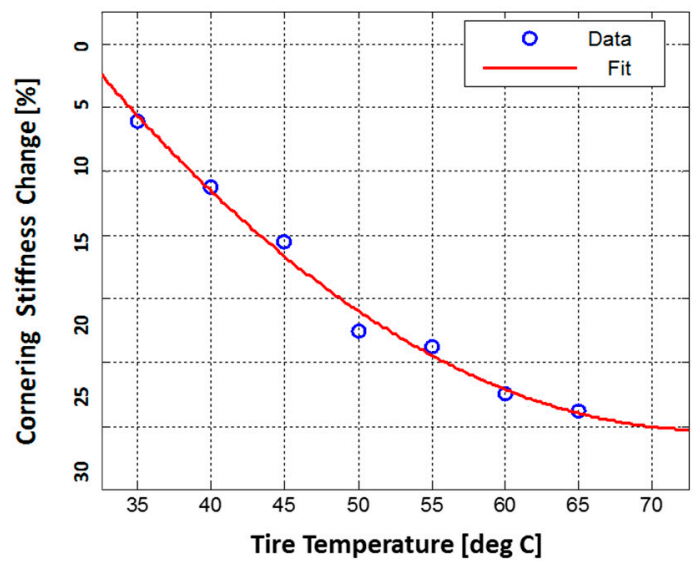

Figure 19. Model fitting results—-temperature dependency. 
The final expression for the adapted cornering stiffness term for the Pacejka tire model formulation is shown below.

$$
\begin{gathered}
B C D=\left(\begin{array}{c}
\left(a_{311} y^{2}+a_{312} y+a_{313}\right) x^{2}+\left(a_{321} y^{2}+a_{322} y+a_{323}\right) x \\
+\left(a_{331} y^{2}+a_{332} y+a_{333}\right)
\end{array}\right) \times \\
\sin \left(2 \arctan \left(\frac{F_{z}}{\left(\left(a_{411} y^{2}+a_{412} y+a_{413}\right) x+\left(a_{421} y^{2}+a_{422} y+a_{423}\right)\right)}\right)\right) \times \\
\left(b_{11} z^{2}+b_{12} z+b_{13}\right)
\end{gathered}
$$

where $\mathrm{x}=$ pressure, $\mathrm{y}=$ tread depth and $\mathrm{z}=$ temperature.

The model inputs include: tire inflation pressure, tread depth, tire load, tire inner liner temperature, and tire ID (required for using tire specific model coefficients). The temperature information available from tire mounted sensor systems typically consists of tire cavity air pressure temperature and/or the tire inner-liner temperature. The temperature measurement of interest here for model adaptation purposes is the tire surface temperature, i.e. the temperature at the tire-road interface. It is proposed to use an empirical model to predict the tire surface temperature. The model requires the following inputs:

- Inner liner temperature (available from tire attached sensor systems)

- Ambient temperature (from the vehicle controller area network (CAN))

- Frictional energy (estimated using the vehicle CAN signals)

- Forward velocity and vehicle yaw-rate (from the vehicle CAN)

- Temperature at previous time-step (internal model calculation)

An artificial neural network (ANN) based model was used to fit the empirical model for tire surface prediction. Previously, researchers have used ANNs for estimating tire parameters such as tire load, tire tread depth and tire-road friction coefficient [32-34]. As an illustrative example, a two-layer recurrent neural network model with 14 neurons is shown here. This model has been trained per-axle using experimental data from hot laps to estimate tire surface temperature. In this study, the carcass (i.e., the tire inner-liner) temperature was collected from wheel-mounted IR sensors for experimental purposes. Other parameters such as ambient temperature, vertical load, forward velocity and slip angles are assumed to be available from vehicle-based sensors and estimators. Frictional energy $\left(E_{x}, E_{y}\right)$ input is based on lateral, longitudinal sliding forces and slip velocities $\left(V_{s x}, V_{s y}\right)$ as shown below.

$$
E_{x}=F_{s x} V_{s x}, E_{y}=F_{s y} V_{s y}
$$

The slip velocities are calculated from approximate values of slip angles and slip ratios. The lateral and longitudinal forces are approximated based on accelerations from the vehicle IMU and vertical load calculated based on load transfer as shown below.

$$
\begin{gathered}
V_{s x}=V_{x}-r \omega, V_{s y}=V_{y}=V_{x} \tan (\alpha) \\
F_{x}=F_{z} \frac{a_{x}}{g}, F_{y}=F_{z} \frac{a_{y}}{g}
\end{gathered}
$$

The proposed structure of the model is shown in Figure 20. 


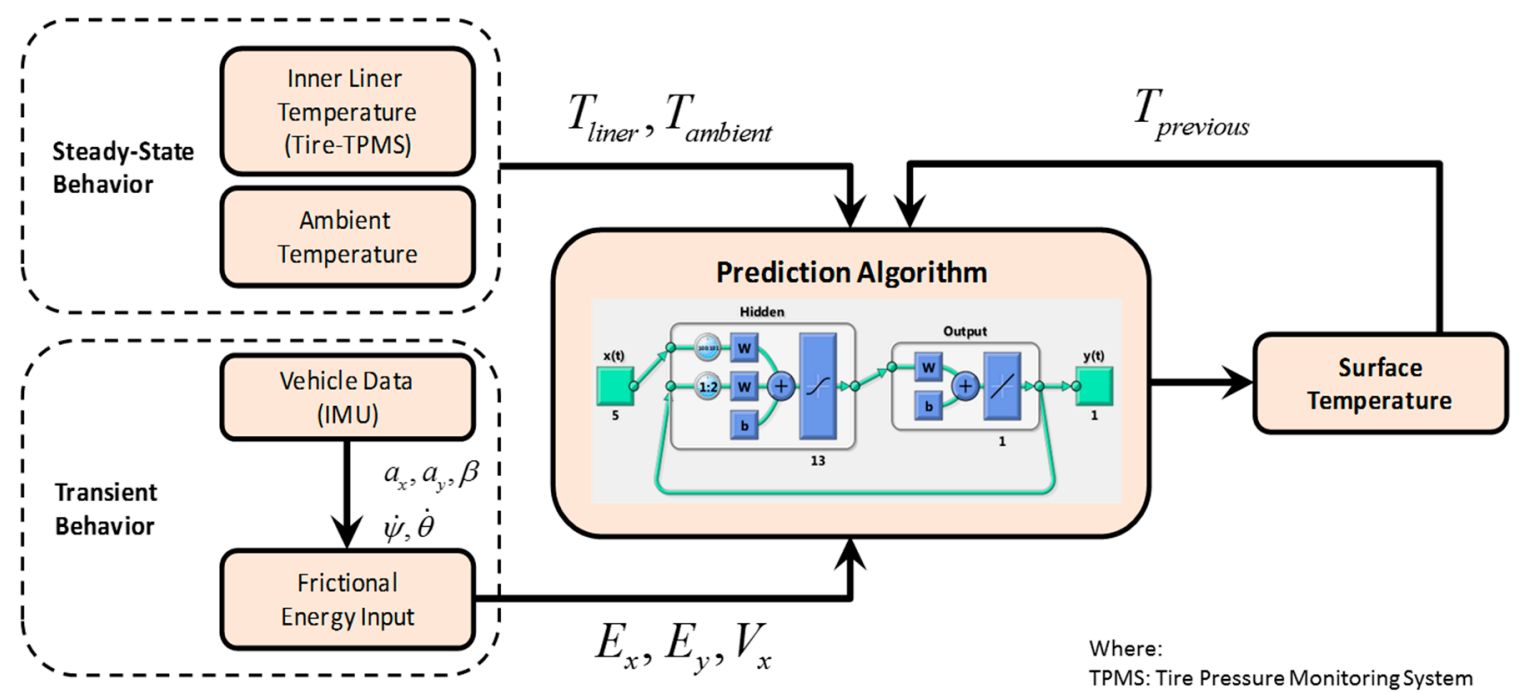

Figure 20. Surface temperature prediction model-flowchart.

For the purpose of experimental validation of the model, vehicle data from a maximum speed lap performed on another day was utilized and the results of the prediction model are shown in Figure 21 for the front-right tire and the rear-left tire, respectively. Although this approach can yield a satisfactory prediction of surface temperature as shown in Figure 21, the accuracy of the model is highly dependent on the availability of reliable training data. The measurement of carcass temperature by tire attached sensors also plays a crucial role as any errors can accumulate errors in the system. A more robust approach would involve utilizing a semi-empirical model that can be fitted to experimental data.
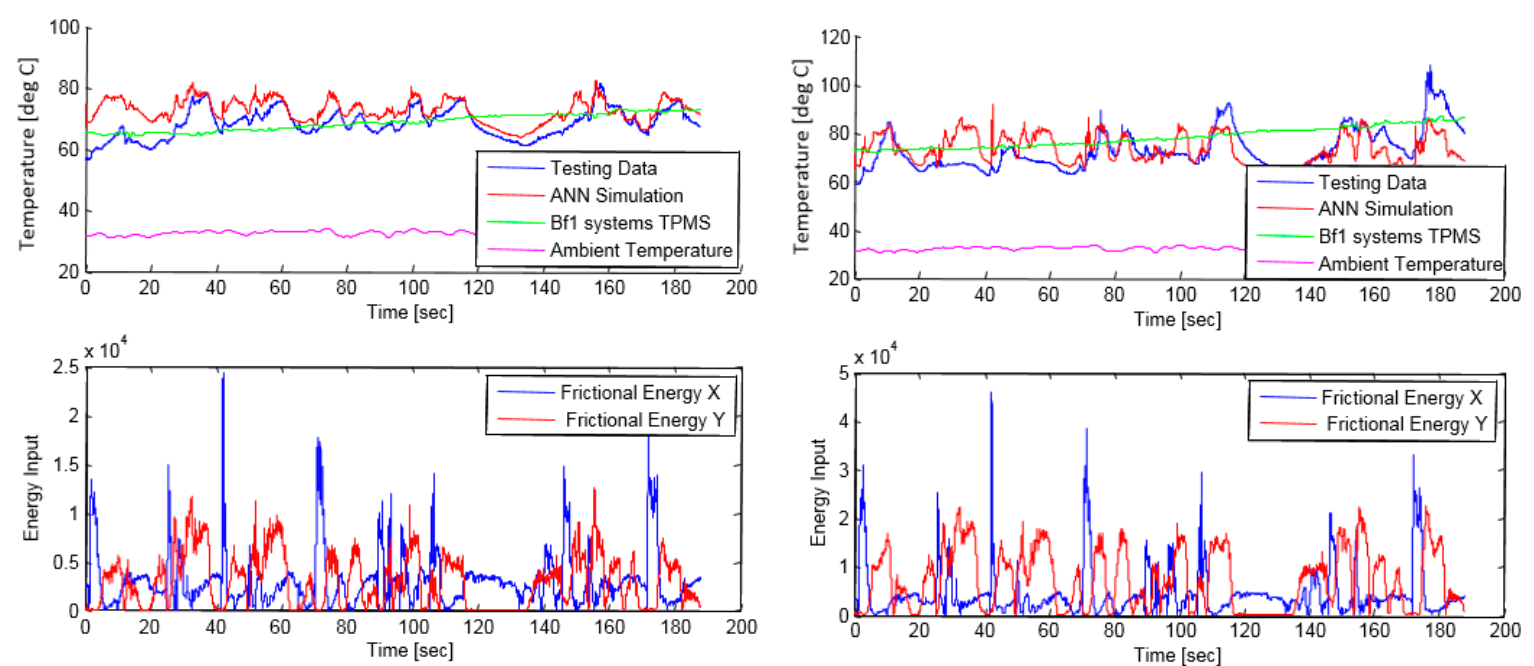

(a)

(b)

Figure 21. Tire surface temperature prediction results: (a) front axle and (b) rear axle. ANN = artificial neural network. BF1 = bf1systems Tire Pressure Monitoring System.

\section{Vehicle Sideslip Angle Estimation Scheme}

The vehicle sideslip angle is estimated using a model-based observer with an adaptive tire model. Adaptation of vehicle and tire parameters is done to overcome the drawback of classical model based observers that are not robust against parameter variations. The block diagram in Figure 22 explicitly shows the estimation process in its entirety. As shown in Figure 22, the vehicle sideslip angle estimator requires the following inputs: 
- Axle lateral force

- Axle cornering stiffness

- Yaw rate and vehicle speed/velocity

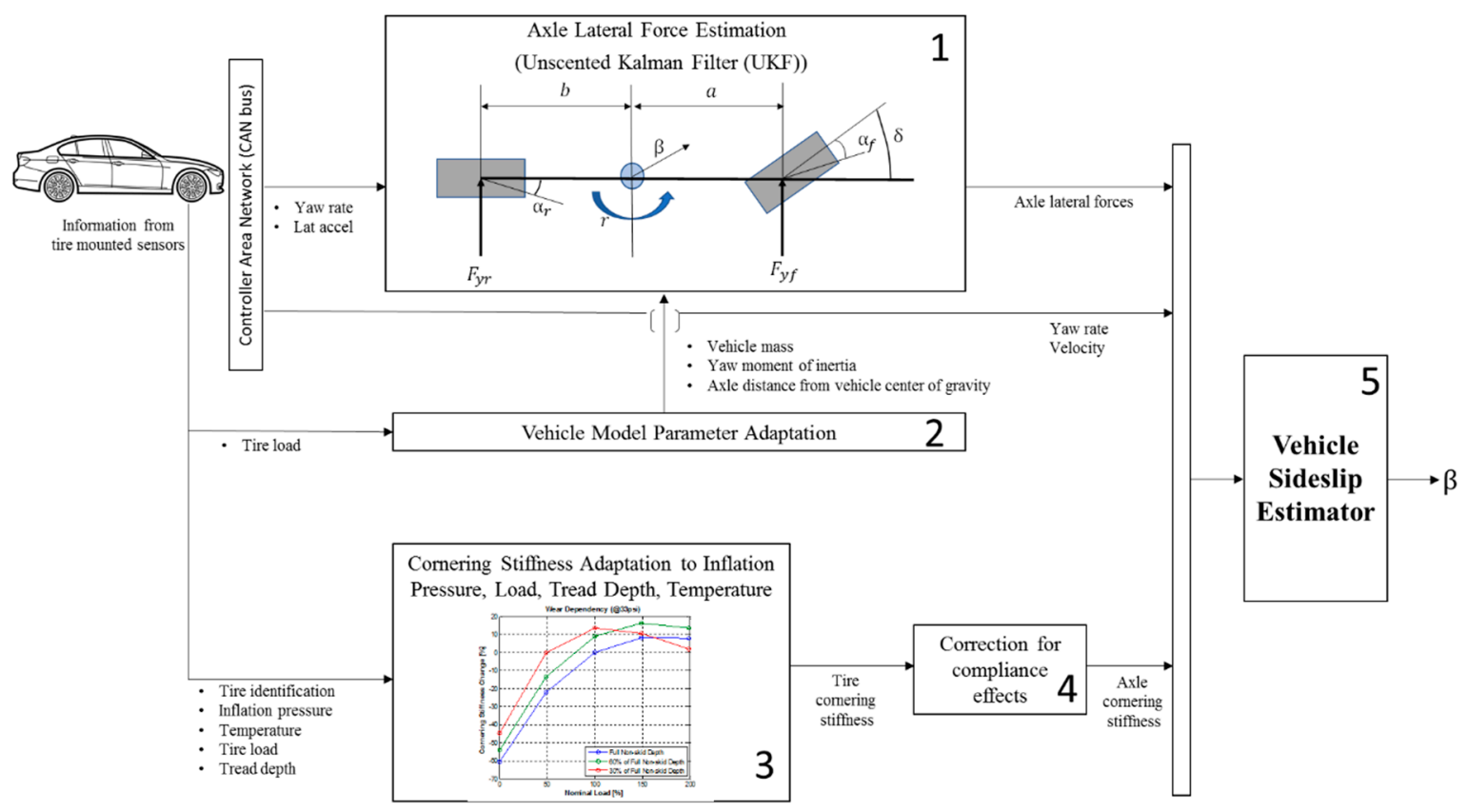

Figure 22. Block diagram of the proposed approach for vehicle sideslip angle estimation.

The first block serves to identify the axle lateral forces using a model-based Unscented Kalman filter (UKF) observer. The observer is built in such a way that it requires no tire force model or prior knowledge of road friction. UKF is chosen over an EKF for the following reasons:

- Both UKF and EKF have been found to be effective at identifying simple or complex vehicle models [35]. Although they use different methods for parameter error covariance estimation, both techniques have identical convergence characteristics and yield near-identical models.

- However, unlike an EKF-based observer, an UKF-based observer avoids the need to calculate Jacobians and is computationally less expensive and easier to implement.

The simplified equation for yaw acceleration based on the bicycle model is as follows:

$$
I_{z} \dot{r}=F_{y f} a-F_{y r} b
$$

where F_yf and F_yr are the axle lateral forces, I_z is the yaw moment inertia and $a$ and $b$ are the distances of the front and rear axles from the vehicle's center of gravity.

Tire forces are modelled with a random walk model [36,37].

$$
\begin{aligned}
& \dot{F_{y f}}=0 \\
& \dot{F_{y r}}=0
\end{aligned}
$$

To build a model based UKF, the model equations are converted to discrete form by the first-order Euler method as:

$$
\begin{gathered}
x_{k}=f_{k-1}\left(x_{k}, u_{k}\right)+v_{k} \\
y_{k}=h\left(x_{k}, u_{k}\right)+w_{k}
\end{gathered}
$$


The state vector $x_{k \prime \prime}$ at each time instant $k$ comprises of yaw rate, front axle lateral force and rear axle lateral force:

$$
x_{k}=\left[r, F_{y f}, F_{y r}\right]^{T}
$$

The measurement vector $y_{k}$ comprises of yaw rate and lateral acceleration:

$$
y_{k}=\left[r, a_{y}\right]^{T}
$$

Once the system is discretized using the first-order Euler approximation with sampling time $\Delta t$, $f(\cdot)$ becomes:

$$
\begin{gathered}
r_{k}=r_{k-1}+\Delta t\left(\frac{F_{y f k-1} a-F_{y r k-1} b}{I_{Z}}\right) \\
F_{y f k}=F_{y f k-1} \\
F_{y r k}=F_{y r k-1}
\end{gathered}
$$

The measurement equations are given as:

$$
\begin{gathered}
h_{1}=r_{k} \\
h_{2}=\left(F_{y f k}+F_{y r k}\right) / m
\end{gathered}
$$

For satisfactory working of the UKF, it is important to tune the process noise covariance matrix $Q$ and measurement noise covariance matrix $R$. Since yaw rate is modeled using system dynamic equations, low uncertainty is assigned to it. However, axle lateral forces are not modeled at all, hence, they are given high uncertainties. The process and measurement noises are assumed to be constant and uncorrelated; therefore, the off-diagonal elements are assigned to 0 . The measurement noise matrix $R$ in terms of standard deviation of the measured signal is given as:

$$
R=\left[\begin{array}{cc}
\sigma_{r}^{2} & 0 \\
0 & \sigma_{a_{y}}^{2}
\end{array}\right]
$$

After careful tuning, the following values of $Q$ and $R$ gave desirable results:

$$
Q=10 e-03\left[\begin{array}{ccc}
0.001 & 0 & 0 \\
0 & 15 e 7 & 0 \\
0 & 0 & 15 e 7
\end{array}\right], R=\left[\begin{array}{cc}
0.01 & 0 \\
0 & 0.01
\end{array}\right]
$$

In addition to the $Q$ and $R$ matrices, there are some other parameters for tuning in UKF. The values of these parameters used for this study are given in Table 7.

Table 7. UKF tuning parameters.

\begin{tabular}{cc}
\hline Parameter & Value \\
\hline$\alpha$ & $1 \times 10^{-3}$ \\
\hline$\beta$ & 2 \\
\hline $\mathrm{K}$ & 0 \\
\hline
\end{tabular}

The second block provides information about key model parameters, namely, vehicle mass, yaw, moment of inertia and axle distances from the vehicle's center of gravity. With information about individual tire loads from tire mounted sensors (Figure 7), the vehicle inertial parameters can be precisely estimated, thus making the proposed model robust against parameter variations.

The third block contains the cornering stiffness adaptation model, as already explained in Section 3 of this paper. The fourth block adjusts the modelled tire cornering stiffness by using scaling factors that account for compliance effects [38] due to the suspension, steering system and the road roughness 
effects. This is important since the adaptation model presented in Section 3 is based on measurement data from an indoor Flat-Trac ${ }^{\circ}$ machine. The stiffness (commonly known as the axle cornering stiffness) comprises of the tire cornering stiffness and the compliance effects, which are hereby accounted for in this block. These scaling factors were identified through controlled vehicle tests. During these tests, International Organization for Standardization (ISO) maneuvers were used to identify the front and rear axle cornering stiffness of the vehicle (Figure 23). The instrumentation used is the same as described in Figure 1.
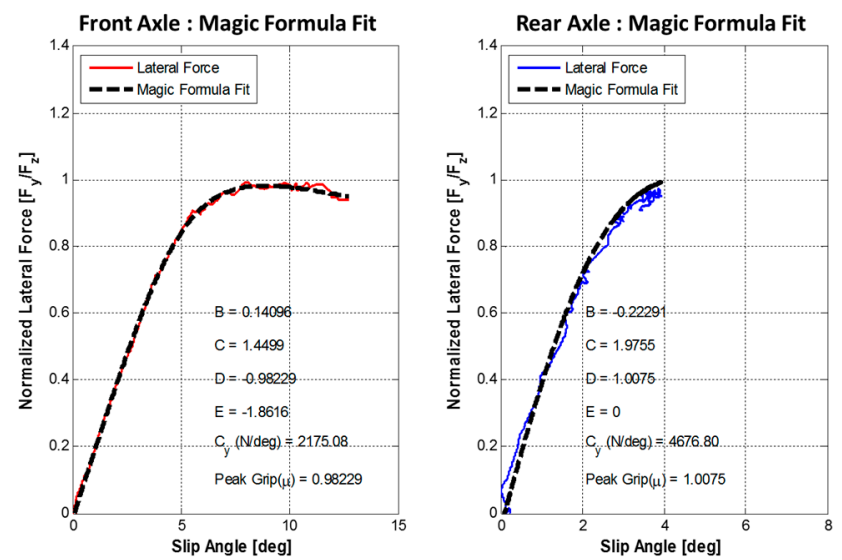

(a)
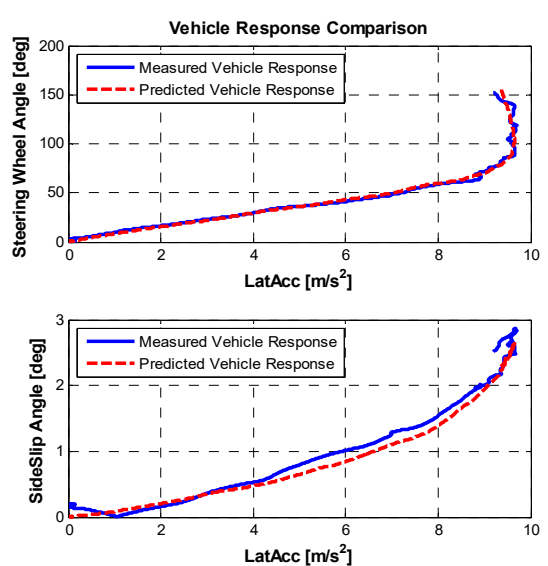

(b)

Figure 23. Vehicle axle cornering stiffness identification through steady state tests. (a) Axle lateral stiffness identification. (b) Fitted model vaidation.

Finally, the fifth block makes use of the estimations provided by the first and the fourth block and measurements available on the vehicle controller area network (CAN) Bus are used to estimate the vehicle sideslip angle.

The rear tire slip angle can be expressed in terms of the vehicle sideslip angle as:

$$
\alpha_{r}=-\beta+\frac{r b}{v_{x}}
$$

The tire forces were modelled using the nonlinear Magic Formula expression, which has the general form:

$$
F(\alpha)=D \sin (C \arctan (B \alpha(1-E)+E \arctan (B \alpha)))
$$

where $D$ refers to the crest factor, $C$ refers to the form factor, $B$ is the stiffness factor, and $E$ is the curvature factor.

For an understeered vehicle, the front axle saturates before the rear axle. Hence, the rear axle curvature factor $(E)$ is set to 0 . The expression for the rear axle simplifies to:

$$
F_{y r}=D_{r} \sin \left(C_{r} \arctan \left(B_{r} \alpha_{r}\right)\right)
$$

Re-arranging the above equation, we can get the expression for the rear tire slip angle as:

$$
\alpha_{r}=\frac{1}{B_{r}} \tan \left(\frac{1}{C_{r}} \arcsin \left(\frac{F_{y r}}{D_{r}}\right)\right)
$$

Combining Equation (21) and Equation (24), we get an updated expression for the vehicle sideslip angle as:

$$
\beta=\frac{r b}{v_{x}}-\frac{1}{B_{r}} \tan \left(\frac{1}{C_{r}} \arcsin \left(\frac{F_{y r}}{D_{r}}\right)\right)
$$


To use the above expression for sideslip estimation, adaptation of individual Pacejka's Magic Formula coefficients $(B, C, D, E)$ is required. Using the same procedure as described in Section 3 of the paper, the scaling factors were calculated, and are given according to the formula:

$$
\begin{aligned}
& B=\left(1+q_{B F_{z}}\left(\frac{F_{z}-F_{z o}}{F_{z o}}\right)\right) \cdot\left(1+q_{B P}\left(\frac{P-P_{o}}{P_{o}}\right)\right) \cdot\left(1+q_{B T}\left(\frac{T-T_{o}}{T_{o}}\right)\right) \cdot\left(1+q_{B W}\left(\frac{W-W_{o}}{W_{o}}\right)\right) \cdot B_{o} \\
& D=\left(1+q_{D F_{z}}\left(\frac{F_{z}-F_{z o}}{F_{z o}}\right)\right) \cdot\left(1+q_{D P}\left(\frac{P-P_{o}}{P_{o}}\right)\right) \cdot\left(1+q_{D T 1}\left(\frac{T-T_{o}}{T_{o}}\right)+q_{D T 2}\left(\frac{T-T_{o}}{T_{o}}\right)^{2}\right) . \\
& \left(1+q_{D W}\left(\frac{W-W_{o}}{W_{o}}\right)\right) \cdot D_{o} \\
& E=\left(1+q_{E F_{z}}\left(\frac{F_{z}-F_{z o}}{F_{z o}}\right)\right) \cdot\left(1+q_{E P}\left(\frac{P-P_{o}}{P_{o}}\right)\right) \cdot\left(1+q_{E T}\left(\frac{T-T_{o}}{T_{o}}\right)\right) \text {. } \\
& \left(1+q_{E W}\left(\frac{W-W_{o}}{W_{o}}\right)\right) \cdot E_{O} \\
& B C D=\left(1+q_{B C D F_{z} 1}\left(\frac{F_{z}-F_{z o}}{F_{z o}}\right)+q_{B C D F_{z} 2}\left(\frac{F_{z}-F_{z o}}{F_{z o}}\right)^{2}\right) \cdot\left(1+q_{B C D P}\left(\frac{P-P_{o}}{P_{o}}\right)\right) . \\
& \left(1+q_{B C D T}\left(\frac{T-T_{o}}{T_{o}}\right)\right) \cdot\left(1+q_{B C D W}\left(\frac{W-W_{o}}{W_{o}}\right)\right) \cdot B C D_{o} \\
& C=\frac{B C D}{B \cdot D}
\end{aligned}
$$

where

$q_{B C D F_{z}} 1$ : fit parameters,

$F_{z}, P T W$ : current operating values of load, pressure, temperature and tread depth,

$F_{z o}, P_{o} T_{o} W_{o}$ : Nominal values of load, pressure, temperature and tread depth, $B_{o} C_{o} D_{o} E_{o}$ : Magic Formula parameters at nominal conditions.

The performance of the sideslip estimator based on Equation (25) was evaluated during a ramp steer maneuver test and found to reliably estimate the sideslip angle (Figure 24).

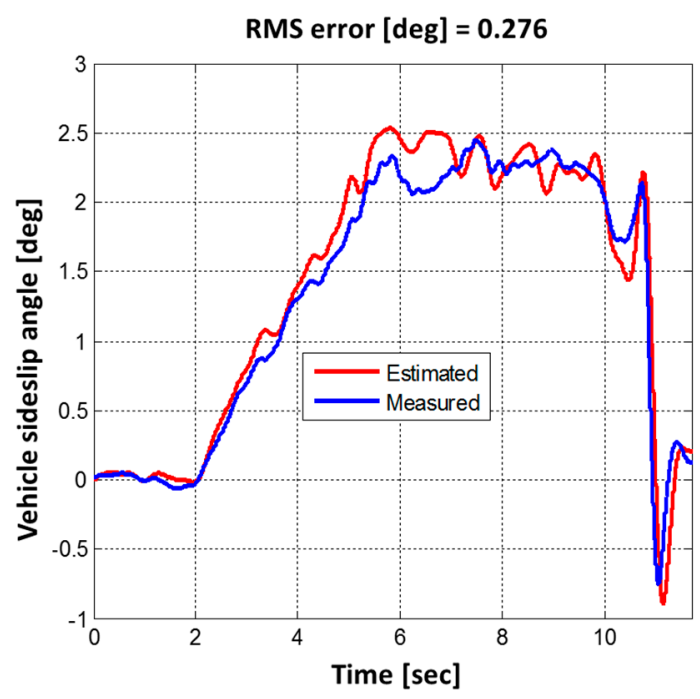

Figure 24. Ramp steer test-vehicle sideslip angle estimate comparison.

Future Research Steps

To further enhance the robustness of the vehicle sideslip angle observer, it is proposed to get a direct estimate of the rear tire slip angle from tire mounted sensors and used that as a feedback signal. Preliminary studies have revealed that the lateral acceleration signal shows a strong correlation with the tire slip angle (Figure 25). 


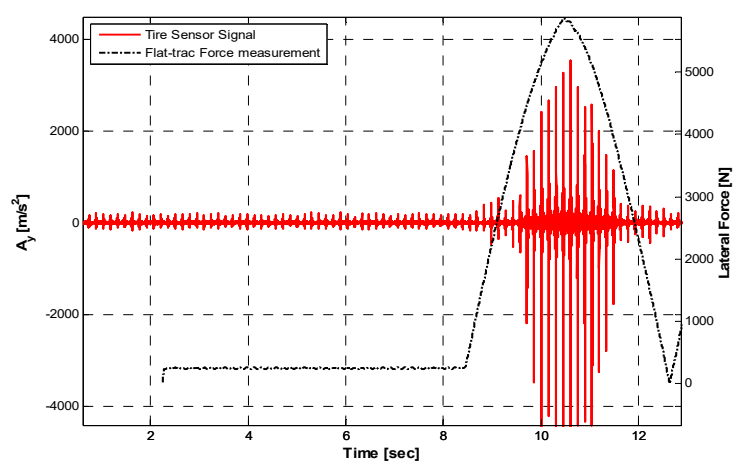

(a)

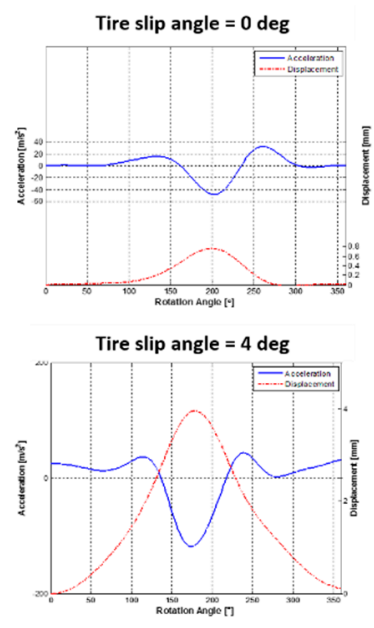

(b)
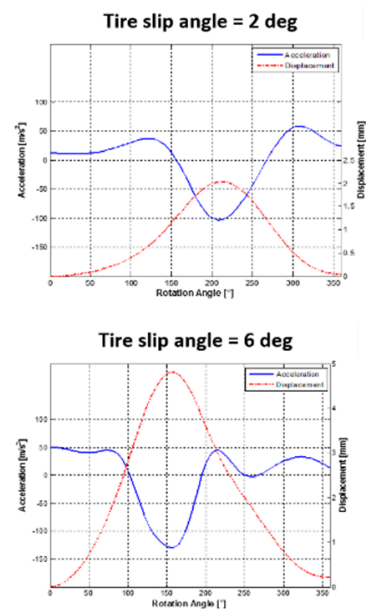

Figure 25. (a) Lateral acceleration profile-tire slip angle sweep test and (b) recovering lateral displacement of the tire footprint from the acceleration signal at different tire slip angles.

There are also strong indications that tire mounted sensors can be used for extracting road friction/road condition information under low slip, i.e. low excitation conditions (Table 8).

Table 8. State-of-the-Art Literature Review-Intelligent Tires.

\begin{tabular}{ccc}
\hline State Estimated & Underlying Physics & Reference \\
\hline Tire road friction & $\begin{array}{c}\text { Friction potential estimated through frequency } \\
\text { domain analysis of the accelerometer signals }\end{array}$ & {$[39-41]$} \\
Tire aquaplaning propensity & $\begin{array}{c}\text { Remaining tire road contact length is } \\
\text { determined based on the tangential } \\
\text { acceleration signal }\end{array}$ & {$[39,42]$} \\
Water depth & $\begin{array}{l}\text { To detect the presence of water in the tire-road } \\
\text { contact, the lateral acceleration signal is utilized. } \\
\text { Since normal excitation from the road surface is } \\
\text { lowest in the lateral direction, all external } \\
\text { excitation produces rather noticeable difference. }\end{array}$ & {$[39]$} \\
\hline
\end{tabular}

Knowledge of road friction would be extremely useful for adapting the tire model parameters to changing road friction conditions and thereby ensuring robust estimation performance of the vehicle sideslip angle. This will also be further examined in future work.

\section{Conclusions}

This paper presents a novel framework for vehicle sideslip angle estimation. The presented framework combines an adaptive tire model, a UKF-based axle force observer and data from tire mounted sensors. Tire model adaptation is achieved by making extensions to the Magic Formula, by accounting for variations in the tire inflation pressure, load, tread depth and temperature. Predictions with the adapted tire model were validated by running experiments on the Flat-Trac ${ }^{\circ}$ machine. The benefits of using an adaptive tire model for sideslip angle estimation are demonstrated through experimental tests. The performance of the observer is satisfactory, both in transient and steady state maneuvers. Future work will focus on measuring tire slip angle and road friction information using tire mounted sensors and using that information to further enhance the robustness of the vehicle sideslip angle observer.

Although the use of tire data for state estimation presents potential improvements in the model-based observer performance, sufficient caution must be practiced in their commercial 
implementation to ensure robust tire identification and data transmission with adequate fallback options.

Funding: This research received no external funding.

Conflicts of Interest: The author declare no conflict of interest.

\section{References}

1. Piyabongkarn, D.; Rajesh, R.; John, A.G.; Jae, Y.L. Development and experimental evaluation of a slip angle estimator for vehicle stability control. IEEE Trans. Control Syst. Technol. 2009, 17, 78-88. [CrossRef]

2. Selmanaj, D.; Matteo, C.; Giulio, P.; Sergio, M.S. Vehicle sideslip estimation: A kinematic based approach. Control Eng. Pract. 2017, 67, 1-12. [CrossRef]

3. Oh, J.; Choi, S.B. Dynamic sensor zeroing algorithm of 6D IMU mounted on ground vehicles. Int. J. Automot. Technol. 2013, 14, 221-231. [CrossRef]

4. Sierra, C.; Tseng, E.; Jain, A.; Peng, H. Cornering stiffness estimation based on vehicle lateral dynamics. Veh. Syst. Dyn. 2006, 44, 24-38. [CrossRef]

5. Lundquist, C.; Schön, T.B. Recursive identification of cornering stiffness parameters for an enhanced single track model. IFAC Proc. Volumes 2009, 42, 1726-1731. [CrossRef]

6. Viehweider, A.; Nam, K.; Fujimoto, H.; Hori, Y. Evaluation of a betaless instantaneous cornering stiffness estimation scheme for electric vehicles. In Proceedings of the 2012 9th France-Japan \& 7th Europe-Asia Congress on Mechatronics (MECATRONICS) / 13th Int'l Workshop on Research and Education in Mechatronics (REM), Paris, France, 21-23 November 2012.

7. Jain, S. Estimation of vehicle handling states. Master's Thesis, Delft University of Technology, Delft, the Nederland, 2014.

8. Wan, E.A.; Rudolph, V.D.M. The unscented Kalman filter for nonlinear estimation. In Proceedings of the IEEE 2000 Adaptive Systems for Signal Processing, Communications, and Control Symposium (Cat. No.00EX373), Lake Louise, AB, Canada, 4 October 2000.

9. Bechtloff, J.; Ackermann, C.; Isermann, R. Adaptive state observers for driving dynamics-online estimation of tire parameters under real conditions. In 6th International Munich Chassis Symposium 2015; Springer Vieweg: Wiesbaden, Germany, 2015.

10. Bechtoff, J.; Koenig, L.; Isermann, R. Cornering Stiffness and Sideslip Angle Estimation for Integrated Vehicle Dynamics Control. IFAC-PapersOnLine 2016, 49, 297-304. [CrossRef]

11. Goodyear Dunlop Reveals Intelligent Tire Concept at Geneva Motor Show. Available online: https://www.goodyear.eu/corporate_emea/news-press/articles/goodyear-dunlop-reveals-intelligenttire-concept-at-geneva-motor-show-_156593 (accessed on 8 February 2019).

12. Bridgestone Announces Development of New Technology for Estimating Tire Wear Based on the Concept of CAIS. Available online: https:/ / www.automotiveworld.com/news-releases/bridgestone-announcesdevelopment-new-technology-estimating-tire-wear-based-concept-cais/ (accessed on 8 February 2019).

13. Pirelli Introduces 'Smart' Tires in Geneva. Available online: https:/ /www.moderntiredealer.com/news/721340/ pirelli-introduces-smart-tires-in-geneva-and-will-debut-them-in-the-u-s (accessed on 7 February 2019).

14. Continental iTires: Intelligent Tires Shipped from the Factory. Available online: https:/ /www.continentaltires.com/transport/media-services/newsroom/20160921-itire (accessed on 7 February 2019).

15. Pacejka, H. Tire and Vehicle Dynamics; Elsevier: Oxford, UK, 2005.

16. Schillinger, J.; Rainer, V.L.; Adrian, C.; Joerg, L. Sensor transponder and procedure for measuring tire contact lengths and wheel load. U.S. Patent 7,536,903, 26 May 2009.

17. Wagner, M.; Hendrik, T. Method for monitoring the load of vehicle tires. U.S. Patent 8,742,911, 3 June 2014.

18. Mancosu, F.; Massimo, B.; Daniele, A. Method and system for determining a cornering angle of a tyre during the running of a vehicle. U.S. Patent 8,024,087, 20 September 2011.

19. Hanatsuka, Y.; Hiroshi, M. Road surface condition estimating method, road surface condition estimating tire, road surface condition estimating apparatus, and vehicle control apparatus. U.S. Patent 9,046,457, 2 June 2015.

20. Tebano, R.; Glorgio, A. Method and system for determining the potential friction between a tyre for vehicles and a rolling surface. U.S. Patent 8,626,454, 7 January 2014. 
21. Singh, K.B.; Mustafa, A.A.; Saied, T. An intelligent tire based tire-road friction estimation technique and adaptive wheel slip controller for antilock brake system. J. Dyn. Syst. Meas. Contrl. 2013, 135, 031002. [CrossRef]

22. Teerhuis, A.; Schmeitz, A.J.C.; Molengraft-Luijten, L. Tire state estimation based on measured accelerations at the tire inner liner using an extended Kalman filter design. In Proceedings of the 4th International Tyre Colloquium, Tyre Models for Vehicle Dynamics Analysis, University of Surrey, Guildford, the United Kingdom, 20-21 April 2015.

23. Hanatsuka, Y. Method and apparatus for detecting wear of tire. U.S. Patent 8,061,191, 22 November 2011.

24. Brusarosco, M.; Federico, M. Method and system for wear control of vehicle tyres. U.S. Patent 8,775,017, 8 July 2014.

25. Lehmann, J.; Bernd, L. Method for determining the depth of tread of a vehicle tire with a tire module arranged on the inner side of the tire. U.S. Patent Application 14/642,114, 9 March 2015.

26. I.B.A.o.h. Veld, Enhancing the MF-Swift Tyre Model for Inflation Pressure Changes. Available online: https: / / pure.tue.nl/ws/files/46975582/674114-1.pdf (accessed on 1 November 2007).

27. Février, P.; Martin, H.; Fandard, G. Method for simulating the thermomechanical behaviour of a tyre rolling on the ground. U.S. patent US8290756B2, 16 October 2012.

28. Février, P. Thermal and Mechanical Tire Force \& Moment Model presentation. In Proceedings of the 4th IPG Technology Conference, Ettlingen, Baden-Württemberg, Germany, 23-24 September 2008.

29. Sebastien, C. Tire Thermal Analysis And Modeling. Master's Thesis, Chalmers University of Technology, Göteborg, Sweden, 2011.

30. Mizuno, M. Development of tire side force model based on magic formula with the influence of tire surface temperature. RED Review of Toyota CRDL 2003, 38, 17-22.

31. Sorniotti, A.; Velardocchia, M. Enhanced Tire Brush Model for Vehicle Dynamics Simulation; SAE Technical Paper; SAE World Congress \& Exhibition: Detroit, MI, USA, 2008. [CrossRef]

32. Pasterkamp, W.R.; Hans, B.P. Application of neural networks in the estimation of tire/road friction using the tire as sensor; SAE Technical Paper; SAE International Congress and Exposition: Detroit, MI, USA, 1997.

33. Singh, K.B. Development of an intelligent tire based tire-vehicle state estimator for application to global chassis control. Master's Thesis, Virginia Tech, Blacksburg, VA, USA, 2012.

34. Singh, K.B. Tire wear state estimation system utilizing cornering stiffness and method. U.S. Patent 13/973,262, 26 February 2015.

35. Bogdanski, K.; Matthew, C.B. Kalman and particle filtering methods for full vehicle and tyre identification. Veh. Syst. Dyn. 2017, 56,1-22. [CrossRef]

36. Doumiati, M.; Victorino, A.; Daniel, L.; Baffet, G.; Charara, A. Observers for vehicle tyre/road forces estimation: Experimental validation. Veh. Syst. Dyn. 2010, 48, 1345-1378. [CrossRef]

37. Cho, W.; Jangyeol, Y.; Seongjin, Y.; Bongyeong, K.; Kyongsu, Y. Estimation of tire forces for application to vehicle stability control. IEEE Trans. Veh. Technol. 2010, 59, 638-649.

38. Niessen, B.C.; Jansen, S.T.H.; Besselink, I.J.M.; Schmeitz, A.J.C.; Nijmeijer, H. An enhanced generic single track vehicle model and its parameter identification for 15 different passenger cars. In Proceedings of the 11th International Symposium on Advanced Vehicle Control (AVEC 2012), Seoul, Korea, 9 September-9 December 2012.

39. Niskanen, A. Sensing the tyre-road contact by intelligent tyre. Ph.D. Thesis, Aalto University, Espoo, Finland, 2017.

40. Singh, K.B.; Saied, T. Estimation of tire-road friction coefficient and its application in chassis control systems. Syst. Scim Cont. Eng. 2015, 3, 39-61.

41. Hanatsuka, Y.; Yasumichi, W.; Hiroshi, M. Method for estimating road surface condition. U.S. Patent 9,170,102, 27 October 2015.

42. Matilainen, M.; Ari, T. Tyre contact length on dry and wet road surfaces measured by three-axial accelerometer. Mech. Syst. Sig. Process. 2015, 52, 548-558. [CrossRef]

(C) 2019 by the author. Licensee MDPI, Basel, Switzerland. This article is an open access article distributed under the terms and conditions of the Creative Commons Attribution (CC BY) license (http:/ / creativecommons.org/licenses/by/4.0/). 